CENTRE for ECONOMIC

$P$ E R F O R M A N C E

CEP Discussion Paper No 1031

December 2010

\title{
International Trade without CES: \\ Estimating Translog Gravity
}

Dennis Novy 


\begin{abstract}
This paper derives a micro-founded gravity equation in general equilibrium based on a translog demand system that allows for endogenous markups and substitution patterns across goods. In contrast to standard CES-based gravity equations, trade is more sensitive to trade costs if the exporting country only provides a small share of the destination country's imports. As a result, trade costs have a heterogeneous impact across country pairs, with some trade flows predicted to be zero. I test the translog gravity equation and find strong empirical support in its favor.
\end{abstract}

Keywords: Translog, gravity, trade costs, distance, trade cost elasticity JEL Classifications: F11, F12, F15

This paper was produced as part of the Centre's Globalisation Programme. The Centre for Economic Performance is financed by the Economic and Social Research Council.

\title{
Acknowledgements
}

I am very grateful for comments by Alberto Behar, Jeffrey Bergstrand, Johannes Bröcker, Natalie Chen, Robert Feenstra, Ana Cecília Fieler, Kyle Handley, Gordon Hanson, Christopher Meissner, Peter Neary, Krishna Pendakur, Joel Rodrigue, Alan Taylor, Christian Volpe Martincus, David Weinstein and Adrian Wood. I am also grateful for comments by seminar participants at the London School of Economics, Kiel, Loughborough, Oxford, Valencia, Warwick, the 2010 CESifo Global Economy conference, the 2010 Econometric Society World Congress, the 2010 NBER Summer Institute and the 2010 Rocky Mountain Empirical Trade conference. I gratefully acknowledge research support from the Economic and Social Research Council, Grant RES-00022-3112.

Dennis Novy is a Visitor with the Globalisation Programme at the Centre for Economic Performance, London School of Economics. He is an assistant professor in the Economics Department at the University of Warwick.

Published by

Centre for Economic Performance

London School of Economics and Political Science

Houghton Street

London WC2A 2AE

All rights reserved. No part of this publication may be reproduced, stored in a retrieval system or transmitted in any form or by any means without the prior permission in writing of the publisher nor be issued to the public or circulated in any form other than that in which it is published.

Requests for permission to reproduce any article or part of the Working Paper should be sent to the editor at the above address.

(C) D. Novy, submitted 2010 


\section{Introduction}

For decades, gravity equations have been used as a workhorse model of international trade. They relate bilateral trade flows to country-specific characteristics of the exporters and importers such as economic size, and to bilateral characteristics such as trade frictions between the trading partners. A large body of empirical literature is devoted to understanding the impact of trade frictions on international trade. The impact of distance and geography, currency unions, free trade agreements and WTO membership have all been studied in great detail with the help of gravity equations.

Theoretical foundations for gravity equations are manifold. In fact, various prominent trade models of recent years predict gravity equations in equilibrium. These models include the Ricardian framework by Eaton and Kortum (2002), the multilateral resistance framework by Anderson and van Wincoop (2003), as well as the model with heterogeneous firms by Chaney (2008). Likewise, Deardorff (1998) argues that a gravity equation also arises from a HeckscherOhlin framework where trade is driven by relative resource endowments. ${ }^{1}$

Although the above trade models make different assumptions as to the motivation behind international trade, they all use constant elasticity of substitution (CES) preferences to describe the demand side of the economy. Not least due to their tractability, CES preferences have proven an enormously useful tool and have had an immense impact on the international trade literature. One common feature of CES preferences is that they translate into a constant elasticity of trade with respect to trade costs. This means that all else being equal, a reduction in trade costs - for instance a uniform tariff cut - has the same proportionate effect on bilateral trade regardless of whether tariffs were initially high or low or whether a country pair traded little or a lot. This is true when the supply side is modeled as a Ricardian framework (Eaton and Kortum, 2002), as a framework with heterogeneous firms (Chaney, 2008) or simply as an endowment economy (Anderson and van Wincoop, 2003).

Yet, recent research has highlighted long-standing concerns over the CES demand specification and the implied constant markups. Attention has been drawn to the idea that a reduction in trade costs, for example through a free trade agreement or falling transportation costs, may lead to an increase in competition and therefore lower markups. Melitz and Ottaviano

\footnotetext{
${ }^{1}$ Also see Bergstrand (1985). Feenstra, Markusen and Rose (2001) as well as Evenett and Keller (2002) also show that various competing trade models lead to gravity equations.
} 
(2008) demonstrate this effect theoretically. Feenstra and Weinstein (2010) provide theory as well as evidence for the US. Badinger (2007) as well as Chen, Imbs and Scott (2009) provide evidence for European countries. This line of research emphasizes more flexible demand systems and variable markups that respond to changes in the competitive environment.

In this paper, I adopt such a demand system and argue that it is fundamental to understanding the trade cost elasticity. In particular, in section 2 I depart from the constant elasticity gravity model and derive a gravity equation from homothetic translog preferences in a general equilibrium framework. Translog preferences were introduced by Christensen, Jorgenson and Lau (1975) in a closed-economy study of consumer demand. ${ }^{2}$ In contrast to CES, translog preferences are more flexible in that they yield endogenous markups and price elasticities, allowing for richer substitution patterns across varieties. When more goods are available for consumers to choose from, markups are lower and price elasticities are higher. This flexibility breaks the constant link between trade flows and trade costs. ${ }^{3}$ Instead, the effect of trade frictions on trade flows varies, depending on how intensely two countries trade with each other. Trade frictions therefore have a heterogeneous trade-impeding impact across country pairs. Despite this increase in complexity, the resulting translog gravity equation is parsimonious and easy to implement with data.

In section 3, I attempt to empirically distinguish translog gravity from the traditional constant elasticity specification. Based on trade flows amongst OECD countries, I find strong evidence against the constant elasticity specification. The results demonstrate that 'one-size-fitsall' trade cost elasticities as implied by CES preferences are not supported by the data. Instead, consistent with translog gravity, I find that the trade cost elasticity increases in absolute size, the less concentrated trade is between two countries. That is, all else being equal, bilateral trade is more sensitive to trade costs if the exporting country provides a smaller share of the destination

\footnotetext{
${ }^{2}$ Recent applications of the translog framework include Feenstra and Weinstein (2010) who are concerned with estimating the welfare gains from increased variety through globalization, Feenstra and Kee (2008) who estimate the effect of expanding export variety on productivity, as well as Bergin and Feenstra (2009) who estimate exchange rate pass-through. More generally, the translog functional form has been used widely in other fields, for example in the productivity literature. See Christensen, Jorgenson and Lau (1971) for an early reference.

${ }^{3}$ Although Melitz and Ottaviano (2008) work with quadratic preferences at the individual product level, their preferences have CES-like characteristics at the aggregate level in the sense that their gravity equation also features a constant trade cost elasticity. It has a zero income elasticity although population can be a demand shifter. Also see Behrens, Mion, Murata and Südekum (2009) for a model with non-homothetic preferences and variable markups but a constant trade cost elasticity. The constant trade cost elasticity is also a feature of the 'generalized gravity equation' based on the nested Cobb-Douglas/CES/Stone-Geary utility function in Bergstrand (1989). See Markusen (1986) for an additional specification with non-homothetic preferences.
} 
country's imports. An implication is that a given trade cost change, for instance a reduction of trade barriers through a free trade agreement, has a heterogeneous impact across country pairs. The translog gravity framework can therefore shed new light on the effect of institutional arrangements such as free trade agreements or WTO membership on international trade. For example, it can help explain why trade liberalizations often lead to relatively larger trade creation amongst country pairs that previously traded relatively little. ${ }^{4}$

Although not explored in this paper, another potentially useful feature of the translog demand system is that it is in principle consistent with zero demand. It is well-known that zeros are widespread in large samples of aggregate bilateral trade, and even more so in samples at the disaggregated level. If bilateral trade costs are sufficiently high, the corresponding import share in translog gravity is zero. This feature is a straightforward implication of the fact that the price elasticity of demand is increasing in price and thus increasing in variable trade costs. In contrast, a CES-based demand system is not consistent with zero trade flows unless fixed costs of exporting are assumed on the supply side (see Helpman, Melitz and Rubinstein, 2008).

The paper builds on the gravity framework by Anderson and van Wincoop (2003), but instead of CES it relies on the homothetic translog demand system employed by Feenstra (2003). Another related paper in the literature is by Gohin and Féménia (2009) who develop a demand equation based on Deaton and Muellbauer's (1980) almost ideal demand system and estimate it with data on intra-European Union trade in cheese products. They also find evidence against the restrictive assumptions underlying the CES-based gravity approach and stress the role of variable price elasticities. But in contrast to my paper, they adopt a partial equilibrium approach and abstract from trade costs. Volpe Martincus and Estevadeordal (2009) use a translog revenue function to study specialization patterns in Latin American manufacturing industries in response to trade liberalization policies, but they do not consider gravity equations. Lo (1990) models shopping travel behavior in a partial equilibrium spatial translog model with varying elasticities of substitution across destination pairs. But her approach does not lead to a gravity equation.

\footnotetext{
${ }^{4}$ Komorovska, Kuiper and van Tongeren (2007) refer to the 'small shares stay small' problem as the inability of CES-based demand systems to generate substantial trade creation in response to significant trade liberalization if initial trade flows were small. In contrast, translog demand predicts large trade responses if initial flows were small. Kehoe and Ruhl (2009) find evidence consistent with this prediction in an analysis of trade growth at the four-digit industry level in the wake of the North American Free Trade Agreement and other major trade liberalizations.
} 


\section{Translog Preferences and Trade Costs}

This section outlines the general equilibrium translog model and derives the theoretical gravity equation based on an endowment economy framework. Following Diewert (1976) and Feenstra (2003), I assume a translog expenditure function. As Bergin and Feenstra (2000) note, the translog demand structure employed here is more concave than the CES. It can be rationalized as a second-order approximation to an arbitrary expenditure system (see Diewert, 1976).

I assume there are $J$ countries in the world with $j=1, \ldots, J$ and $J \geq 2$. Each country is endowed with at least one differentiated good but may have arbitrarily many, and the number of goods may vary across countries. ${ }^{5}$ Let $\left[N_{j-1}+1, N_{j}\right]$ denote the range of goods of country $j$, with $N_{j-1} \leq N_{j}$ and $N_{0} \equiv 0 . N_{J} \equiv N$ denotes the total number of goods in the world. The translog expenditure function is given by

(1) $\ln \left(E_{j}\right)=\ln \left(U_{j}\right)+\alpha_{0 j}+\sum_{m=1}^{N} \alpha_{m} \ln \left(p_{m j}\right)+\frac{1}{2} \sum_{m=1}^{N} \sum_{k=1}^{N} \gamma_{k m} \ln \left(p_{m j}\right) \ln \left(p_{k j}\right)$, where $U_{j}$ is the utility level of country $j$ with $m$ and $k$ indexing goods and $\gamma_{k m}=\gamma_{m k}$. The price of good $m$ when delivered in country $j$ is denoted by $p_{m j}$. I assume trade frictions such that $p_{m j}=t_{m j} p_{m}$, where $p_{m}$ denotes the net price for good $m$ and $t_{m j} \geq 1 \forall m, j$ is the variable trade cost factor. I furthermore assume symmetry across goods from the same origin country $i$ in the sense that $p_{m}=p_{i}$ if $m \in\left[N_{i-1}+1, N_{i}\right]$, and that trade costs to country $j$ are the same for all the goods from origin country $i$, i.e., $t_{m j}=t_{i j}$ if $m \in\left[N_{i-1}+1, N_{i}\right]$. But I allow trade costs $t_{i j}$ to be asymmetric for a given country pair such that $t_{i j} \neq t_{j i}$ is possible.

As in Feenstra (2003), to ensure an expenditure function with homogeneity of degree one I impose the conditions:

(2) $\sum_{m=1}^{N} \alpha_{m}=1$, and $\sum_{k=1}^{N} \gamma_{k m}=0$.

In addition, I require that all goods enter 'symmetrically' in the $\gamma_{k m}$ coefficients. Following Feenstra (2003), I therefore impose the additional restrictions:

(3) $\gamma_{m m}=-\frac{\gamma}{N}(N-1) \forall m$ and $\gamma_{k m}=\frac{\gamma}{N} \forall k \neq m$ with $\gamma>0$.

\footnotetext{
${ }^{5} \mathrm{CES}$ can be rationalized as an aggregator for a set of underlying goods so that the assumption of one differentiated good per country as in Anderson and van Wincoop (2003) is reasonable. However, that assumption would not be harmless with translog demand. The number of goods is therefore allowed to vary across countries.
} 
It can be easily verified that these additional restrictions satisfy the homogeneity condition in (2). ${ }^{6}$

The expenditure share $s_{m j}$ of country $j$ for good $m$ can be obtained by differentiating the expenditure function (1) with respect to $\ln \left(p_{m j}\right)$ :

$$
\text { (4) } s_{m j}=\alpha_{m}+\sum_{k=1}^{N} \gamma_{k m} \ln \left(p_{k j}\right)
$$

Let $x_{i j}$ denote the value of trade from country $i$ to country $j$, and $y_{j}$ is the income of country $j$ equal to expenditure $E_{j}$. The import share $x_{i j} / y_{j}$ is then the sum of expenditure shares $s_{m j}$ over the range of goods that originate from country $i$ :

$$
\text { (5) } \frac{x_{i j}}{y_{j}}=\sum_{m=N_{i-1}+1}^{N_{i}} s_{m j}=\sum_{m=N_{i-1}+1}^{N_{i}}\left(\alpha_{m}+\sum_{k=1}^{N} \gamma_{k m} \ln \left(p_{k j}\right)\right) \text {. }
$$

To close the model, I impose market clearing:

$$
\text { (6) } y_{i}=\sum_{j=1}^{J} x_{i j} \forall i
$$

\subsection{The Translog Gravity Equation}

To obtain the gravity equation, I substitute the import shares from equation (5) into the market-clearing condition (6) to solve for the general equilibrium. Using $p_{k j}=t_{k j} p_{k}$, I then solve for the net prices $p_{k}$ and substitute them back into the import share (5). This solution procedure is similar to the one adopted by Anderson and van Wincoop (2003) for their CES-based model. The Technical Appendix provides a detailed derivation.

As the final result, I obtain a translog 'gravity' equation for import shares as

$$
\text { (7) } \frac{x_{i j}}{y_{j}}=\frac{y_{i}}{y^{W}}-m_{i} \ln \left(t_{i j}\right)+m_{i} \ln \left(T_{j}\right)+m_{i} \sum_{s=1}^{J} \frac{y_{s}}{y^{W}} \ln \left(\frac{t_{i s}}{T_{s}}\right) \text {, }
$$

where $y^{W}$ denotes world income, defined as $y^{W} \equiv \sum_{j=1}^{J} y_{j}$, and $n_{i} \equiv N_{i}-N_{i-1}$ denotes the number of goods of country $i$. The variable $\ln \left(T_{j}\right)$ is a weighted average of (logarithmic) trade costs over the trading partners of country $j$ akin to inward multilateral resistance in Anderson and van Wincoop (2003). As the Technical Appendix shows, it is given by

\footnotetext{
${ }^{6}$ The assumption of $\gamma>0$ ensures that the price elasticity of demand exceeds unity. The estimation results below confirm this assumption. The elasticity is also increasing in price (see Feenstra, 2003).
} 
(8) $\ln \left(T_{j}\right)=\frac{1}{N} \sum_{k=1}^{N} \ln \left(t_{k j}\right)=\sum_{s=1}^{J} \frac{n_{s}}{N} \ln \left(t_{s j}\right)$.

Note that the last term on the right-hand side of equation (7) only varies across the exporting countries $i$ but not across the importing countries $j$. However, the third term on the right-hand side of equation (7), $\gamma n_{i} \ln \left(T_{j}\right)$, varies across both.

To be clear, I refer to expression (7) as a 'gravity' equation although its appearance differs from traditional gravity equations in two respects. First, the left-hand side variable is the import share $x_{i j} / y_{j}$ and not the bilateral trade flow $x_{i j}$. Second, the right-hand variables are not multiplicatively linked. However, expression (7) and traditional gravity equations have in common that they relate the extent of bilateral trade to both bilateral variables such as trade costs as well as to country-specific variables such as the exporter's and importer's incomes and multilateral resistance.

\subsection{A Comparison to Gravity Equations with a Constant Trade Cost Elasticity}

The important feature of the translog gravity equation is that the import share on the lefthand side of equation (7) is specified in levels and not in logarithmic form, while logarithmic trade costs appear on the right-hand side. This stands in contrast to 'traditional' gravity equations. For example, Anderson and van Wincoop (2003) derive the following gravity equation:

$$
\text { (9) } x_{i j}=\frac{y_{i} y_{j}}{y^{W}}\left(\frac{t_{i j}}{\Pi_{i} P_{j}}\right)^{1-\sigma} \text {, }
$$

where $\Pi_{i}$ and $P_{j}$ are outward and inward multilateral resistance variables, respectively, and $\sigma$ is the elasticity of substitution from the CES utility function on which their model is based. ${ }^{7}$ To be more easily comparable to the translog gravity equation (7), I divide the standard gravity equation (9) by $y_{j}$ and take logarithms to arrive at

$$
\text { (10) } \ln \left(\frac{x_{i j}}{y_{j}}\right)=\ln \left(\frac{y_{i}}{y^{W}}\right)-(\sigma-1) \ln \left(t_{i j}\right)+(\sigma-1) \ln \left(\Pi_{i}\right)+(\sigma-1) \ln \left(P_{j}\right) \text {. }
$$

Although the dependent variable of gravity equations in the literature is typically $\ln \left(x_{i j}\right)$ as opposed to the logarithmic import $\operatorname{share} \ln \left(x_{i j} / y_{j}\right)$, I will nevertheless refer to the CES-based

\footnotetext{
${ }^{7}$ Note that in the absence of trade costs $\left(t_{i j}=1 \forall i, j\right)$, the CES and translog gravity equations coincide as $x_{i j} / y_{j}=y_{i} / y^{W}$.
} 
gravity equation (10) as the 'standard' or 'traditional' specification as opposed to the translog specification in equation (7).

The log-linear form of equation (10) is the key difference to the translog gravity equation (7). The log-linear form is also a feature of the Ricardian model by Eaton and Kortum (2002) as well as the heterogeneous firms model by Chaney (2008). ${ }^{8}$ It implies a trade cost elasticity $\eta$ that is constant, where $\eta$ is defined as ${ }^{9}$

(11) $\eta \equiv \frac{\mathrm{d} \ln \left(x_{i j} / y_{j}\right)}{\mathrm{d} \ln \left(t_{i j}\right)}$.

Thus, the traditional gravity equation (10) implies $\eta^{C E S}=-(\sigma-1) .{ }^{10}$

However, translog gravity breaks this constant link between trade flows and trade costs. The translog (TL) trade cost elasticity follows from equation (7) as

(12) $\eta_{i j}^{T L}=-m_{i} /\left(x_{i j} / y_{j}\right)$.

It thus varies across observations. Specifically, ceteris paribus the absolute value of the elasticity, $\left|\eta_{i j}^{T L}\right|$, decreases as the import share grows larger. Intuitively, given the size $y_{j}$ of the importing country and the number of exported goods $n_{i}$, a large trade flow $x_{i j}$ means that the exporting country enjoys a relatively powerful market position. Demand for the exporter's goods is buoyant, and consumers do not react strongly to price changes induced by changes in trade costs. On the contrary, a small trade flow $x_{i j}$ means that demand for an exporting country's goods is weak, and consumers are sensitive to price changes. As a result, small exporters are hit harder by rising trade costs and find it more difficult to defend their market share.

\section{Estimation}

In this section, I first estimate a translog gravity regression as derived in equation (7), and separately I also estimate a traditional gravity regression as in equation (10). I then proceed to

\footnotetext{
${ }^{8}$ These models employ a CES preference structure. The trade cost coefficient in Eaton and Kortum (2002) is governed by the technology parameter $\theta$, which is the shape parameter from the underlying Fréchet distribution. The trade cost elasticities in Chaney (2008) and Melitz and Ottaviano (2008) are governed by the parameter that determines the degree of firm heterogeneity, drawn from a Pareto distribution. Other differences include, for instance, the presence of bilateral fixed trade costs in the Chaney gravity equation.

${ }^{9}$ The elasticity $\eta$ as defined here focuses on the direct effect of $t_{i j}$ on $x_{i j} / y_{j}$. It abstracts from the indirect effect of $t_{i j}$ on $x_{i j} / y_{j}$ through the multilateral resistance terms. These are general equilibrium effects that operate in both the CES and the translog frameworks. See section 3.5 for a discussion.

${ }^{10}$ The gravity equation by Eaton and Kortum (2002) implies $\eta^{E K}=-\theta$. Likewise, the gravity equations by Chaney (2008) and Melitz and Ottaviano (2008) also imply a constant trade cost elasticity, given by the Pareto shape parameter.
} 
econometrically discriminate the two models by testing the hypothesis whether the trade cost elasticity is constant (as predicted by the traditional gravity model) or variable (as predicted by the translog gravity model).

\subsection{Data}

I use exports amongst 28 OECD countries for the year 2000, sourced from the IMF Direction of Trade Statistics and denominated in US dollars. These include all OECD countries except for the Czech Republic and Turkey. The maximum number of bilateral observations is $28 * 27=756$, but seven are missing so that the sample includes 749 observations in total. ${ }^{11}$ Income data for the year 2000 are taken from the IMF International Financial Statistics.

I follow the gravity literature by modeling the trade cost factor $t_{i j}$ as a log-linear function of observable trade cost proxies (see Anderson and van Wincoop, 2003 and 2004). For the baseline specification, I use bilateral great-circle distance dist $_{i j}$ between capital cities as the sole trade cost proxy, taken from www.indo.com/distance. For other specifications I add an adjacency dummy $a d j_{i j}$ that takes on the value one if countries $i$ and $j$ share a land border. The trade cost function can thus be written as

(13) $\ln \left(t_{i j}\right)=\rho \ln \left(d i s t_{i j}\right)+\delta a d j_{i j}$, where $\rho$ denotes the distance elasticity of trade costs and $\delta$ is the adjacency coefficient. Since distance and adjacency do not vary over time, the focus is on cross-sectional variation in trade costs.

To estimate the translog gravity equation (7), I also require data on $n_{i}$, the number of goods that originate from country $i$. Naturally, such data are not easy to measure and the theory does not provide guidance as to how it should be measured. However, Hummels and Klenow (2005) construct a measure of the extensive margin across countries based on shipments in more than 5,000 six-digit product categories from 126 exporting countries to 59 importing countries for the year 1995. The extensive margin is measured by weighting categories of goods by their overall importance in exports, consistent with the methodology developed by Feenstra (1994). Their Table A1 reports the extensive margin of country $i$ relative to the rest of the world. I use

\footnotetext{
11 The countries are Australia, Austria, Belgium, Canada, Denmark, Finland, France, Germany, Greece, Hungary, Iceland, Ireland, Italy, Japan, Korea, Luxembourg, Mexico, the Netherlands, New Zealand, Norway, Poland, Portugal, the Slovak Republic, Spain, Sweden, Switzerland, the United Kingdom and the United States. As some data for the Czech Republic and Turkey were missing, these countries were dropped from the sample.
} 
this fraction as a proxy for $n_{i}$. Hummels and Klenow (2005) document that the extensive margin tends to be larger for big countries. For example, the extensive margin measure is 0.91 for the United States, 0.79 for Germany and 0.72 for Japan but only 0.05 for Iceland.

As an alternative, I construct an additional measure of the extensive margin. Instead of the weighting scheme used by Hummels and Klenow (2005), I devise an unweighted count of six-digit product categories. The correlation between the two measures stands at 77 percent. As a robustness check, I use this alternative measure in the regressions that correspond to those described below, and the results are qualitatively very similar. ${ }^{12}$

\subsection{Estimating Translog Gravity}

The first and last terms on the right-hand side of equation (7) can be captured by an exporter fixed effect $S_{i}$ since they do not vary over the importing country $j$ :

$$
S_{i} \equiv \frac{y_{i}}{y^{W}}+m_{i} \sum_{s=1}^{J} \frac{y_{s}}{y^{W}} \ln \left(\frac{t_{i s}}{T_{s}}\right)
$$

I substitute this exporter fixed effect into equation (7) to obtain

$$
\text { (14) } \frac{x_{i j}}{y_{j}}=-m m_{i} \ln \left(t_{i j}\right)+m m_{i} \ln \left(T_{j}\right)+S_{i}+\varepsilon_{i j}
$$

where I also add a mean-zero error term $\varepsilon_{i j}$. Then I substitute the trade cost function (13) into the multilateral resistance term (8). This yields

$$
\ln \left(T_{j}\right)=\rho \ln \left(T_{j}^{d i s t}\right)+\delta T_{j}^{a d j},
$$

where the terms on the right-hand side are defined as

$$
\text { (15) } \ln \left(T_{j}^{d i s t}\right) \equiv \sum_{s=1}^{J} \frac{n_{s}}{N} \ln \left(d i s t_{s j}\right) \text { and } T_{j}^{a d j} \equiv \sum_{s=1}^{J} \frac{n_{s}}{N} a d j_{s j} \text {. }
$$

Using the trade cost function (13) once again for $\ln \left(t_{i j}\right)$, the translog estimating equation follows as

$$
\text { (16) } \frac{x_{i j}}{y_{j}}=-\gamma \rho n_{i} \ln \left(d i s t_{i j}\right)+\gamma \rho n_{i} \ln \left(T_{j}^{d i s t}\right)-\gamma \delta n_{i} a d j_{i j}+\gamma \delta n_{i} T_{j}^{a d j}+S_{i}+\varepsilon_{i j} \text {. }
$$

\footnotetext{
${ }^{12}$ I use UN Comtrade bilateral export data at the six-digit level for the year 2000 (HS 1996 classification). I exclude very small bilateral trade flows (those with values below 10,000 US dollars) since those tend to disappear frequently from one year to the next. Following Hummels and Klenow (2005), I normalize the extensive margin measure by constructing it relative to the total number of six-digit product categories that exist across all countries (5130 categories). This alternative measure is 0.99 for the US, 0.95 for Germany, 0.89 for Japan and 0.10 for Iceland.
} 
I construct the explanatory variables $n_{i} \ln \left(\right.$ dist $\left._{i j}\right)$ and $n_{i} a d j_{i j}$ by multiplying the underlying trade cost variables by the extensive margin proxy $n_{i}$ taken from Hummels and Klenow (2005). The $\ln \left(T_{j}^{d i s t}\right)$ and $T_{j}^{a d j}$ terms are constructed for each country $j$ according to equation (15) and then multiplied by the extensive margin proxy $n_{i}$.

Table 1 presents the regression results. Column 1 estimates equation (16) with bilateral distance as the only trade cost proxy. As expected, import shares tend to be significantly lower for more distant country pairs. Column 2 adds the adjacency dummy. As typically found in gravity estimations, this variable is positive and significant. The coefficients of the individual regressors and the corresponding multilateral resistance regressors are similar in magnitude as predicted by estimating equation (16). For example, the distance coefficient in column 1 is estimated at -0.0296 , whereas the corresponding trade cost index term is 0.0207 . These two values are reasonably close in absolute magnitude, although a formal test of their equality is rejected ( $\mathrm{p}$-value $=0.00$ ). However, for the two adjacency regressors in column 2 a test of their equality in absolute magnitude cannot be rejected ( $p$-value=0.81).

As an additional check, I adopt a related estimating equation where the dependent variable is the import share $x_{i j} / y_{j}$ divided by the extensive margin measure $n_{i}$ for the exporting country. The resulting variable can be interpreted as the average import share per good of the exporting country. From equation (16) I obtain

$$
\text { (17) } \frac{x_{i j} / y_{j}}{n_{i}}=-\gamma \rho \ln \left(\operatorname{dist}_{i j}\right)-\gamma \delta a d j_{i j}+\hat{S}_{i}+\hat{S}_{j}+v_{i j} \text {, }
$$

where $v_{i j}$ denotes the error term. The exporter fixed effect $\hat{S}_{i}=S_{i} / n_{i}$ now absorbs the extensive margin measure $n_{i}$, and the multilateral resistance terms associated with distance and adjacency can be captured by an importer fixed effect $\hat{S}_{j}$ given by

$$
\hat{S}_{j} \equiv \gamma \rho \ln \left(T_{j}^{d i s t}\right)+\gamma \delta T_{j}^{a d j}
$$

The regression results are reported in columns 3 and 4. As before, distance enters with the expected negative coefficient and adjacency with a positive coefficient. As a final check, in columns 5 and 6 I make the simplifying assumption that each country is endowed with only one 
$\operatorname{good}\left(n_{i}=1 \forall i\right) .{ }^{13}$ Naturally, the magnitudes of the coefficients shift but they retain their signs and significance. Overall, given the sizeable degree of explanatory power of the regressions with an R-squared of 50 percent or more, I conclude that the translog gravity equation passes its first test of being reasonable.

Apart from translog gravity, I also estimate the standard gravity specification. I substitute the trade cost function (13) into equation (10) to arrive at the estimating equation for 'traditional' gravity:

(18) $\ln \left(\frac{x_{i j}}{y_{j}}\right)=-(\sigma-1) \rho \ln \left(\operatorname{dist}_{i j}\right)+-(\sigma-1) \delta a d j_{i j}+\tilde{S}_{i}+\tilde{S}_{j}+\xi_{i j}$,

where I add an error term $\xi_{i j}{ }^{14} \tilde{S}_{i}$ and $\tilde{S}_{j}$ are exporter and importer fixed effects defined as

$$
\begin{aligned}
& \tilde{S}_{i} \equiv \ln \left(\frac{y_{i}}{y^{W}}\right)+(\sigma-1) \ln \left(\Pi_{i}\right), \\
& \tilde{S}_{j} \equiv(\sigma-1) \ln \left(P_{j}\right) .
\end{aligned}
$$

The logarithmic form of the dependent variable is the key difference to the translog specification in equation (16).

Regression results for equation (18) are presented in columns 1 and 2 of Table 2. As typical, bilateral distance is negatively related to import shares with a coefficient in the vicinity of -1 , whereas adjacency is associated with higher shares. For completeness, in columns 3 and 4 I change the dependent variable to the log import share per good of the exporting country, $\left.\ln \left(\left(x_{i j} / y_{j}\right) / n_{i}\right)\right)$. The measure for $n_{i}$ is entirely absorbed by the exporter fixed effects so that the coefficients of interests and their standard errors remain the same. Consistent with the gravity literature, the log-linear regressions in Table 2 have a high explanatory power with R-squareds close to 90 percent. $^{15}$

\footnotetext{
${ }^{13}$ Alternatively, I could also set $n_{i}=n$ where $n$ is any arbitrary positive integer. Since the regression is linear, the estimated coefficients would simply be scaled by the factor $1 / n$.

${ }^{14}$ An estimating equation based on the Eaton and Kortum (2002) model would merely replace $\sigma-1$ by $\theta$. Here, the crucial feature is that the trade cost elasticity is constant. This feature would also arise for the other gravity models mentioned above.

${ }^{15}$ Although the R-squareds associated with the regressions in Table 1 are around 55 percent and thus lower, they are not directly comparable to those in Table 2 because the dependent variables are not the same.
} 


\subsection{Testing Traditional vs. Translog Gravity}

The next objective is to test translog gravity against the traditional gravity specification. The test centers on the question of whether the trade cost elasticity is constant. As equation (12) shows, translog gravity implies that the absolute value of the trade cost elasticity decreases in the import share per good, i.e.,

$$
\frac{\partial\left|\eta_{i j}^{T L}\right|}{\partial\left(\frac{x_{i j} / y_{j}}{n_{i}}\right)}<0 .
$$

In contrast, standard gravity equations imply a constant trade cost elasticity. I form two hypotheses, A and B, to test whether the elasticity is indeed constant. Hypothesis A is based on the standard gravity estimation as in equation (18), while hypothesis B is based on the translog gravity estimation as in equation (17).

The premise of hypothesis A is that the standard gravity model is correct and that trade cost elasticities should not vary systematically. To implement this test, I allow the trade cost coefficients in the traditional specification (18) to vary across import shares per good. Since estimating a separate distance coefficient for each observation would leave no degrees of freedom, I allow the distance coefficient to vary over intervals of import shares per good. That is, I set the distance coefficient for observation $i j$ equal to $\lambda_{h}$ if this observation falls in the $h$ th interval with $h=1, \ldots, H$. $H$ denotes the interval with the largest import shares per good, and the number of intervals is sufficiently small to leave enough degrees of freedom in the estimation. I also add interval fixed effects. For simplicity, I drop the adjacency dummy from the notation so that the estimating equation becomes

$$
\text { (19) } \ln \left(\frac{x_{i j}}{y_{j}}\right)=-\lambda_{h} \ln \left(d i s t_{i j}\right)+\widetilde{S}_{i}+\widetilde{S}_{j}+\widetilde{S}_{h}+\omega_{i j} \text {, }
$$

where $\tilde{S}_{h}$ denotes the interval fixed effect and $\omega_{i j}$ is an error term. Hypothesis A states - as predicted by the traditional gravity model - that the $\lambda_{h}$ distance coefficients should not vary across import share intervals, i.e., $\lambda_{1}=\lambda_{2}=\ldots=\lambda_{H}$. The alternative is - as predicted by the translog gravity model - that the $\lambda_{h}$ distance coefficients should vary systematically across intervals as implied by equation (12). Specifically, the absolute elasticity should decrease across the intervals, i.e., $\lambda_{1}>\lambda_{2}>\ldots>\lambda_{H}$. 
How exactly should the intervals be chosen? If the intervals were chosen based on observed values for import shares, this selection would be based on the dependent variable and would lead to an endogeneity bias in the coefficients of interest, $\lambda_{h}$. More specifically, I carried out Monte Carlo simulations demonstrating that this selection procedure would lead to an upward bias in the distance coefficients (i.e., $\lambda_{h}$ coefficients closer to zero) since both the dependent variable and the interval classification would be positively correlated with the error term. $^{16}$

The endogeneity bias can be avoided if intervals are chosen based on predicted import shares. In particular, I first estimate equation (18) and obtain trade cost coefficients that are common across all observations. Based on those regression results I then predict import shares and divide the sample into $H$ intervals of predicted import shares. By construction, this interval classification is uncorrelated with the residuals of regression (18). Monte Carlo simulations confirm that with this two-stage procedure, estimating equation (19) no longer imparts a bias on the $\lambda_{h}$ coefficients.

Table 3 presents regression results for equation (19) under the assumption of $H=5$, i.e., with five import share intervals. Consistent with equation (12), the intervals in columns 1-4 are chosen based on predicted import shares per good, $\left(x_{i j} / y_{j}\right) / n_{i}$. Like in Table 2, columns 3 and 4 only differ from the previous two in that they use the import share per good as the dependent variable. But due to the log-linearity the measure for $n_{i}$ is absorbed by the exporter fixed effects such that the coefficients of interest and their standard errors are not affected, only the Rsquared. Nevertheless, I report the results for completeness. As a robustness check, the intervals in columns 5 and 6 are chosen based on predicted import shares only, $x_{i j} / y_{j}$.

Columns 1, 3 and 5 report results with distance as the only trade cost regressor. A clear pattern arises: the $\lambda_{h}$ distance coefficients decline in absolute value for intervals with larger import shares, as predicted by the translog model. For example, in column 1 the distance elasticity for the smallest import shares is -1.496 whereas it shrinks in magnitude to -1.079 for

\footnotetext{
${ }^{16}$ I simulated import shares under the assumption that the Anderson and van Wincoop (2003) gravity equation (10) is the true model, using distance as the trade cost proxy based on the trade cost function (13) and assuming various arbitrary parameter values for the distance elasticity $\rho$ and the elasticity of substitution $\sigma$. The variance of the $\log$ normal error term was chosen to match the R-squared of around 90 percent as in Table 2. I then divided the sample into intervals based on the simulated import shares and ran regression (19) with OLS, replicating this procedure 1000 times. The resulting bias can be severe, in some cases halving the magnitudes of coefficients compared to their true values.
} 
the largest import shares. Hypothesis A, which states that the distance coefficients are equal to each other, can be clearly rejected ( $\mathrm{p}$-value $=0.01$ in columns 1 and 3 , p-value $=0.00$ in column 5).

Columns 2, 4 and 6 add adjacency. Since no adjacent country pair in the sample falls into the interval capturing the smallest predicted import shares, the corresponding regressor drops out. The addition of the adjacency dummies does not alter the pattern of distance coefficients. Those still decline monotonically in magnitude across all specifications and their equality can be rejected ( $\mathrm{p}$-value $=0.00$ in columns 2,4 and 6). There is no such monotonic pattern for the adjacency coefficients, but their point estimates for intervals 2 and 3 are substantially larger than those for intervals 4 and $5 .{ }^{17}$ Overall, their equality can be clearly rejected in columns 2 and 4 (pvalue $=0.00)$ although not in column $6(\mathrm{p}$-value $=0.34)$. But the specifications in columns 2 and 4 are preferable since those are based on intervals of predicted import shares per good, as warranted by equation (12).

I also experimented with different numbers of intervals, in particular $H=3$ and $H=10$ (not reported here). The results are not qualitatively affected and the same coefficient patterns arise as in Table 3. This suggests that the systematic inequality of trade cost elasticities across import share intervals is a robust feature of the data. In summary, therefore, the results provide evidence against the constant elasticity gravity specification and in favor of the translog gravity model.

Hypothesis B is based on the translog gravity estimating equation (17). Its premise is that the translog specification is correct and that trade cost coefficients in that estimation should not vary systematically across import shares. I adopt the same strategy as above in that I allow the trade cost coefficients to vary across intervals $h=1, \ldots, H$ of import shares per good, also adding interval fixed effects. For simplicity, I again drop the adjacency variable from the notation so that the estimating equation becomes

$$
\text { (20) } \frac{x_{i j} / y_{j}}{n_{i}}=-\kappa_{h} \ln \left(\text { dist }_{i j}\right)+\hat{S}_{i}+\hat{S}_{j}+\hat{S}_{h}+v_{i j},
$$

where $\kappa_{h}$ denotes the trade cost coefficients, $\hat{S}_{h}$ denotes the interval fixed effect and $v_{i j}$ is an error term. Hypothesis B states - as predicted by the translog gravity model - that the $\kappa_{h}$ distance coefficients should not vary across intervals of import shares per good, i.e., $\kappa_{l}=\kappa_{2}=\ldots=\kappa_{H}$. The

\footnotetext{
${ }^{17}$ A clear monotonic pattern for the adjacency coefficients does emerge in columns 2 and 4 of Table 3 if the alternative, unweighted measure is used for the extensive margin $n_{i}$ (see section 3.1).
} 
alternative is - as implied by the standard gravity model - that the magnitude of the $\kappa_{h}$ distance coefficients should increase in the import share per good. ${ }^{18}$

As with hypothesis A, one needs to be careful in constructing the intervals. If they were chosen based on observed values of import shares per good, one would incur an upward endogeneity bias in the coefficients of interest, $\kappa_{h}$. But this bias can be avoided if one first estimates equation (17) to obtain common trade cost coefficients, predicts the corresponding import shares and then divides the sample into $H$ intervals of predicted import shares per good. I verified the validity of this estimation strategy with Monte Carlo simulations. ${ }^{19}$

Table 4 a presents regression results for equation (20) under the assumption of $H=5$, i.e., with five import share intervals. In column 1 where distance is the only trade cost regressor, the distance coefficients appear to generally rise in magnitude across import shares and the hypothesis that they are equal can be rejected $(\mathrm{p}$-value $=0.00)$. However, this rejection is driven by the coefficient for the first interval (equal to -0.0449), which deviates most from the other coefficients. Indeed, the hypothesis that the coefficients for intervals 2-5 are equal cannot be rejected ( $p$-value=0.44). Neither can the hypothesis of equality between all distance coefficients be rejected when I rerun regression (20) with more intervals. ${ }^{20}$

In column 2, I add adjacency. Since all adjacent country pairs in the sample fall into the fifth interval, the adjacency variables for the other intervals drop out. With adjacency included, I no longer obtain a monotonic pattern of distance coefficients. In fact, the point estimates for intervals 4 and 5 are smaller in magnitude than for interval 3, and they are not statistically different from each other ( $\mathrm{p}$-value $=0.69$ ). This evidence is inconsistent with the pattern of distance coefficients that one would expect under the constant elasticity gravity model.

\footnotetext{
${ }^{18}$ To see this, divide the constant elasticity gravity equation (9) by $y_{j}$ and take the derivative with respect to $\ln \left(t_{i j}\right)$. The result is $\mathrm{d}\left(x_{i j} / y_{j}\right) / \mathrm{d} \ln \left(t_{i j}\right)=-(\sigma-1) x_{i j} / y_{j}$, implying that the absolute value of this derivative is increasing in $x_{i j} / y_{j}$. In the translog gravity equation (7), this derivative is given by $\mathrm{d}\left(x_{i j} / y_{j}\right) / \mathrm{d} \ln \left(t_{i j}\right)=-\gamma n_{i}$. If constant elasticity gravity were the true specification, then $\gamma n_{i}$ should also be increasing in $x_{i j} / y_{j}$, or equivalently $\gamma$ should be increasing in $\left(x_{i j} / y_{j}\right) / n_{i}$. Thus, in equation (20) the $\kappa_{h}$ distance coefficients should be increasing in $\left(x_{i j} / y_{j}\right) / n_{i}$.

${ }^{19}$ I simulated import shares under the assumption that the translog gravity equation (7) is the true model, using distance as the trade cost proxy based on the trade cost function (13) and assuming various arbitrary values for the distance elasticity $\rho$ and the translog parameter $\gamma$. The variance of the error term was chosen to match the R-squared of around 55 percent as in Table 1. I divided the sample into intervals based on either the simulated import shares or predicted import shares from a first-stage regression of equation (17). I then ran regression (20) with both types of intervals, replicating this procedure 1000 times. Forming intervals based on the simulated import shares leads to a severe upward bias in the $\kappa_{h}$ coefficients.

${ }^{20}$ For example, with $H=10$ the test of coefficient equality cannot be rejected (p-value $=0.24$ ).
} 
In Table 4b I present corresponding results based on equation (16) with $x_{i j} / y_{j}$ as the dependent variable. Multilateral resistance terms now appear as regressors. As in Table 4a, in columns 1 and 2 intervals are chosen based on predicted import shares per good. As a robustness check, the intervals in columns 3 and 4 are chosen based on predicted import shares only. Distance is the only trade cost regressor in columns 1 and 3. Adjacency is added in columns 2 and 4 .

As noted above, if gravity with a constant elasticity were the true underlying model, one should observe a monotonic increase in the absolute distance coefficients across the intervals. However, such a pattern is generally not supported by the estimations. For example, in column 1 the distance coefficient for the first interval (equal to -0.0535) is larger in absolute size than those for intervals 2 and 3 but smaller than those for intervals 4 and 5 . In column 2 the smallest distance coefficient is associated with the second interval (equal to -0.0351); in column 3 the smallest coefficient is for the fourth interval (equal to -0.0332); in column 4 the smallest coefficient is for the second interval (equal to -0.0327). Nevertheless, formal tests of coefficient equality across intervals (i.e., hypothesis B) can still be rejected because the coefficients are tightly estimated.

Overall, the results in Tables 3, 4a and $4 \mathrm{~b}$ appear inconsistent with coefficient patterns one should expect under the constant elasticity gravity model. They instead support the predictions of the translog gravity model. However, as a matter of careful interpretation, the empirical results should first and foremost be seen as evidence against CES rather than in favor of translog. Although consistent with the translog gravity model, of course the results logically do not preclude the possibility of an alternative third model that performs even better than translog. Nevertheless, the translog specification indicates the direction in which the demand side of trade models could sensibly be modified to yield gravity equations with varying trade cost elasticities.

\subsection{Discussion}

The crucial result from the preceding gravity estimations is that a constant 'one-size-fitsall' trade cost elasticity is inconsistent with the data. Instead, the trade cost elasticities vary with the import share, as predicted by translog gravity. What are the implied values for these elasticities? This question can be answered by considering the elasticity expression in equation 
(12). The elasticities $\eta_{i j}$ depend on the translog parameter $\gamma$, the import share $x_{i j} / y_{j}$ and the number of goods of the exporting country $n_{i}$.

The values for $x_{i j} / y_{j}$ and $n_{i}$ are given by the data, and the translog parameter $\gamma$ can be retrieved from the estimated distance coefficient in a translog regression. As the translog estimating equation (16) shows, the coefficient on the variable $n_{i} \ln \left(d i s t_{i j}\right)$ corresponds to the product of the translog parameter $\gamma$ and the distance elasticity of trade costs $\rho$. As an illustration, I take 0.0296 from column 1 of Table 1 as an absolute value for this coefficient, i.e., $\gamma \rho=0.0296$. To be comparable to the gravity literature, I choose a value of $\rho$ that is consistent with typical estimates. Specifically, in standard gravity equations based on equation (18), the distance coefficient corresponds to the parameter combination - $(\sigma-1) \rho$. It is typically estimated to be around -1 (see Disdier and Head, 2008), and in column 1 of Table 2 I obtain a reasonably close estimate of -1.239 for my sample of OECD countries. Under the assumption of an elasticity of substitution equal to $\sigma=8$, which falls approximately in the middle of the range $[5,10]$ as surveyed by Anderson and van Wincoop (2004), the distance coefficient estimate implies $\rho=1.239 /(8-1)=0.177 .{ }^{21}$ The value of the translog parameter then follows as $\gamma=0.0296 / \rho=0.167 .{ }^{22}$ To be clear about my approach, I only choose a value of $\rho$ for illustrative purposes. The analysis below does not qualitatively depend on this particular value.

The trade cost elasticities can now be calculated across different import shares. I first calculate the trade cost elasticity evaluated at the average import share in the sample. This average share is $x_{i j} / y_{j}=0.01$. The average of the extensive margin measure is $n_{i}=0.50$. The trade cost elasticity therefore follows as $\eta_{i j}=-\gamma n_{i} /\left(x_{i j} / y_{j}\right)=-0.167 * 0.50 / 0.01=-8.4 .^{23}$ Thus, if trade costs go down by one percent, ceteris paribus the average import share is expected to increase by 8.4 percent. This value is close to the CES-based trade cost elasticity, $\eta^{C E S}=-(\sigma-1)$, which equals 7 under the assumption of $\sigma=8$. For alternative values of $\sigma$ it is also true that the translog trade cost

\footnotetext{
${ }^{21}$ See Anderson and van Wincoop (2004, Figure 1) for further evidence that $\rho=0.177$ is a reasonable value.

${ }^{22}$ Based on an estimation of supply and demand systems at the 4-digit industry level, Feenstra and Weinstein (2010) yield a median translog coefficient of $\gamma=0.19$. My value of $\gamma=0.167$ is reasonably close and would match Feenstra and Weinstein's (2010) estimate exactly in the case of $\rho=0.156$.

${ }^{23}$ The extensive margin measure taken from Hummels and Klenow (2005) more closely corresponds to the fraction $n_{i} / N$ since they report the extensive margin of country $i$ relative to the rest of the world. However, this does not affect the implied trade cost elasticities. The reason is that the elasticities as expressed in equation (12) depend on the product $\gamma n_{i}$. If $n_{i}$ is multiplied by a constant $(I / N)$, the linear estimation in regression (16) leads to a point estimate of $\gamma$ that is scaled up by the inverse of the constant $(N)$ so that their product is not affected $\left(N \gamma * n_{i} / N=\gamma n_{i}\right)$.
} 
elasticity evaluated at the average import share is close to the underlying CES-based trade cost elasticity. $^{24}$

However, in contrast to the CES specification, the trade cost elasticities based on the translog gravity estimation vary across import shares. A given trade cost reduction therefore has a heterogeneous impact on import shares. As an example, I illustrate this heterogeneity with import shares that involve New Zealand as the importing country. I choose New Zealand because its import shares vary across a relatively broad range so that the heterogeneity of trade cost elasticities can be demonstrated succinctly. Of course, the analysis would be qualitatively similar for other importing countries. The Australian share of New Zealand's imports is the biggest (7.2 percent), followed by the US share (3.8 percent), the Japanese share ( 2.4 percent) and the UK share (0.9 percent).

The corresponding trade cost elasticities, computed in the same way as before, are -1.3 for Australia, -4.0 for the US, -5.0 for Japan and -14.4 for the UK. Figure 1 plots these trade cost elasticities in absolute value against the import shares, adding various additional countries that export to New Zealand. ${ }^{25}$ Dotted lines represent 95 percent confidence intervals computed with the delta method based on the regression in column 1 of Table 1. The figure shows that trade flows are more sensitive to trade costs if import shares are small. The impact of a given trade cost change is therefore heterogeneous across country pairs. This key feature stands in contrast to the trade cost elasticity in the standard CES-based gravity model where it is simply a constant $(\sigma-1=7$ in this case $)$.

\subsection{General Equilibrium Effects}

The trade cost elasticity $\eta$ as defined in equation (11) focuses on the direct impact of a change in trade costs $t_{i j}$ on the import share $x_{i j} / y_{j}$. However, it does not take into account the indirect impact of a trade cost change through general equilibrium effects, as forcefully demonstrated by Anderson and van Wincoop (2003). To illustrate the role of general equilibrium, I decompose how import shares are affected by the direct and indirect effects and how this decomposition varies across import share intervals. But as I clarify further below,

\footnotetext{
${ }^{24}$ For instance, under the assumption of $\sigma=5$, it follows $\rho=0.31$ and $\gamma=0.095$ so that the trade cost elasticity evaluated at the average import share is -4.8 . Under the assumption of $\sigma=10$, it follows $\rho=0.138$ and $\gamma=0.214$ so that the trade cost elasticity is -10.7 .

${ }^{25}$ In order of declining import shares, the other countries are Germany, Italy, Korea and France.
} 
general equilibrium effects are not able to explain the pattern of declining distance coefficients as found in Table 3.

I demonstrate the role of general equilibrium effects based on the constant elasticity gravity model in equation (10). As a simplification I assume trade cost symmetry such that outward and inward multilateral resistance terms are equal $\left(\Pi_{i}=P_{i} \forall i\right)$. As a counterfactual experiment, I will assume a reduction in trade costs $t_{i j}$ for a specific country pair. To understand the effect on the import share, I take the first difference of equation (10) to arrive at

(21) $\Delta \ln \left(\frac{x_{i j}}{y_{j}}\right)=(1-\sigma) \Delta \ln \left(t_{i j}\right)+\Delta \ln \left(\frac{y_{i}}{y^{W}}\right)+\Delta(\sigma-1) \ln \left(P_{i} P_{j}\right)$.

The left-hand side of equation (21) indicates the percentage change of the import share. It can be decomposed into three components. The first term on the right-hand side is the direct effect of the change in bilateral trade costs scaled by $(1-\sigma)$. The second and third terms are the general equilibrium effects, i.e., the change in the exporting country's income share and most importantly the change in multilateral resistance terms scaled by $(\sigma-1)$.

I am interested in how the decomposition in equation (21) varies across import shares. To that end, I first compute an initial equilibrium of trade flows based on the income data for the year 2000 and bilateral distance data for the 28 countries in the sample. Then, for each of the $28 * 27=756$ bilateral observations I compute a counterfactual equilibrium under the assumption that all else being equal, bilateral trade costs for that observation have decreased by one percent, i.e., $\Delta \ln \left(t_{i j}\right)=-0.01$, assuming an elasticity of substitution of $\sigma=8$. I use the trade cost function (13) with distance as the only trade cost variable, assuming a distance elasticity of $\rho=1 / 7 .^{26}$

Table 5 presents the decomposition results that correspond to equation (21). The rows report the average changes for each import share interval. Given the parameter assumption of $\sigma=8$, the direct effect of a one percent drop in bilateral trade costs is an increase in the import share of seven percent across all intervals (see column 2). While changes in the income shares in column 3 do not vary systematically across import shares, the multilateral resistance effects in column 4 are largest in absolute size for the interval capturing the largest import shares. In total,

\footnotetext{
${ }^{26}$ The counterfactual equilibria are computed in the same way as in Anderson and van Wincoop (2003, Appendix B). The required domestic distance data are taken from the CEPII, see http://www.cepii.fr/anglaisgraph/bdd/distances.htm. This distance elasticity is close to the value chosen in section 3.4 for illustrative purposes. The results are qualitatively not sensitive to alternative values. I also experimented with alternative parameter assumptions for the substitution elasticity $(\sigma=5$ and $\sigma=10)$ and different trade cost declines (5 percent and 10 percent). The overall results are qualitatively very similar.
} 
the general equilibrium effects dampen the direct effect for larger import shares (see the total effect in column 1). Intuitively, large countries like Japan and the US are less dependent on international trade such that changes in bilateral trade costs have little effect on multilateral resistance. As large countries are typically associated with small import shares, the indirect general equilibrium effects are often negligible for small import shares. However, for small countries like Iceland and Luxembourg a given change in bilateral trade costs shifts multilateral resistance relatively strongly. As those countries are typically associated with larger import shares, general equilibrium effects tend to be stronger in that case so that the total effect is dampened. The trade cost elasticities in columns $5 \mathrm{a}$ and $5 \mathrm{~b}$ summarize these effects. Columns $6 \mathrm{a}$ and $6 \mathrm{~b}$ report the implied distance elasticities. From equation (18) the direct distance elasticity is simply given by $-(\sigma-1) \rho$, which equals -1 in this case.

It is important to stress that the distance elasticities in Tables 2 and 3 only represent the direct elasticities. General equilibrium effects work in addition to the direct effect and are absorbed by exporter and importer fixed effects. To verify this claim, I conduct Monte Carlo simulations as in section 3.3 for the constant elasticity model. The simulations are now based on the counterfactual scenario that all bilateral trade costs decline by one percent, leaving domestic distances unchanged. Thus, the simulated import shares are shifted by both direct and indirect effects. I then re-estimate gravity regression (19), dividing the sample into five import share intervals and allowing the distance elasticities to vary across these intervals. The results show that the distance coefficients are consistently estimated as the parameter combination $-(\sigma-1) \rho$ across all five intervals. They do not reflect general equilibrium effects. Thus, general equilibrium effects cannot account for the systematic pattern of distance elasticities reported in Table 3.

\subsection{Alternative Trade Cost Functions}

The log-linear trade cost function (13) is the standard specification in the gravity literature. However, I also examine other specifications to ensure that the coefficient patterns in the regression tables do not hinge on this particular functional form.

In the CES-based gravity regressions of Table 3, larger import shares are characterized by smaller distance coefficients in absolute size. As larger import shares are typically found at shorter distances, a conceivable explanation could be that shorter distances are associated with a 
smaller distance elasticity of trade costs, whereas the trade cost function (13) imposes a constant distance elasticity of trade costs due to its log-linear form. As an alternative, I consider a trade cost function that implies a smaller distance elasticity of trade costs at shorter distances:

$$
\text { (22) } \ln \left(t_{i j}\right)=\hat{\rho}\left[\ln \left(\operatorname{dist}_{i j}\right)\right]^{2},
$$

where $\hat{\rho}$ is a parameter to be estimated. Logarithmic trade costs are thus convex in logarithmic distance. I also consider the opposite case of a concave trade cost function. In particular, I adopt a specification in which the level of trade costs depends on logarithmic distance, or equivalently:

$$
\text { (23) } \ln \left(t_{i j}\right)=\tilde{\rho} \ln \left[\ln \left(\text { dist }_{i j}\right)\right]
$$

where $\tilde{\rho}$ is a parameter. This concave specification captures the idea that trade costs might rise disproportionately quickly at short distances and less quickly at long distances (see Hillberry and Hummels, 2008).

I rerun the CES-based gravity equations (18) and (19) that correspond to the first columns in Tables 2 and 3, respectively, using the two alternative trade cost functions (22) and (23) instead of (13). Naturally, the change in the trade cost function affects the magnitudes of the distance coefficients. But for both trade cost functions it is still the case that the distance coefficients tend to decline in absolute value across import shares. ${ }^{27}$ This finding is consistent with the predictions of the translog gravity model and provides further evidence against the notion that trade cost elasticities are equal across import shares.

I also rerun the translog gravity equations (17) and (20) that correspond to column 3 of Table 1 and columns 1 and 2 of Table $4 \mathrm{a}$ using the trade cost functions (22) and (23). Although the magnitudes of the distance coefficients shift in response to the alternative trade cost functions, the coefficient patterns across import share intervals are qualitatively the same as in the previous translog gravity regressions. ${ }^{28}$ Overall, I therefore conclude that the results

\footnotetext{
${ }^{27}$ In the regression corresponding to the first column of Table 2 , the distance coefficients are -0.0819 for trade cost function (22) and -8.8513 for trade cost function (23). In the regression corresponding to the first column of Table 3 , the distance coefficients for $h=1, \ldots, 5$ are $-0.0892,-0.0917,-0.0893,-0.0802$ and -0.0772 for trade cost function (22) and $-12.7899,-10.9773,-10.3685,-9.0189$ and -6.7481 for trade cost function (23). The R-squareds are in the same range as in Tables 2 and 3.

${ }^{28}$ In the regression corresponding to column 3 of Table 1, the distance coefficients are -0.0016 for trade cost function (22) and -0.1876 for trade cost function (23). In the regression corresponding to column 1 of Table $4 \mathrm{a}$, the distance coefficients for $h=1, \ldots, 5$ are $-0.0029,-0.0033,-0.0033,-0.0036$ and -0.0040 for trade cost function (22). As in column 2 of Table $4 \mathrm{a}$, the last three distance coefficients no longer increase monotonically in size if adjacency is included as a regressor, in which case the distance coefficients become $-0.0022,-0.0024,-0.0026,-0.0026$ and -0.0026 . For trade cost function (23), the distance coefficients corresponding to column 1 of Table $4 \mathrm{a}$ are -0.3313 ,
} 
presented in Tables 1-4 are robust to the alternative trade cost functions adopted in equations (22) and (23).

\section{Conclusion}

Leading trade models from the current literature imply a gravity equation that is characterized by a constant elasticity of trade flows with respect to trade costs. This common feature across models is related to the widespread use of CES demand systems. This paper adopts an alternative demand system - translog preferences - and derives the corresponding gravity equation. Due to more flexible substitution patterns across goods, translog gravity breaks the constant trade cost elasticity that is the hallmark of traditional gravity equations. Instead, the elasticity becomes endogenous and depends on the intensity of trade flows between two countries.

In particular, all else being equal, the less two countries trade with each other and the smaller their bilateral import shares, the more sensitive they are to trade costs. I test the translog gravity specification and find evidence that strongly supports this prediction. That is, trade cost elasticities are heterogeneous across import shares, and the traditional specification with a constant trade cost elasticity can be clearly rejected.

The empirical results presented in this paper are based on aggregate trade flows. A natural extension would be an application to more disaggregated data. In that regard, I have obtained some preliminary results based on import shares between OECD countries at the level of 3-digit industries. When I allow gravity distance coefficients for individual industries to vary across import shares in CES-based gravity equations, their absolute values are characterized by the same declining pattern as in Table 3 for industries as diverse as food products, plastic products and electric machinery. This additional evidence suggests that varying trade cost elasticities are a distinguishing feature of international trade data also at the industry level. Exploring industry-level data in more detail along those lines remains as an important topic for future research.

$-0.3781,-0.3761,-0.3852$ and -0.3730 ; and corresponding to column 2 of Table $4 \mathrm{a}$ they are $-0.2543,-0.2839$, $-0.3094,-0.2998$ and -0.2434 . The R-squareds are similar to those in Tables 1 and $4 \mathrm{a}$. 


\section{References}

Anderson, J., van Wincoop, E., 2003. Gravity with Gravitas: A Solution to the Border Puzzle. American Economic Review 93, pp. 170-192.

Anderson, J., van Wincoop, E., 2004. Trade Costs. Journal of Economic Literature 42, pp. 691751.

Badinger, H., 2007. Has the EU's Single Market Programme Fostered Competition? Testing for a Decrease in Mark-up Ratios in EU Industries. Oxford Bulletin of Economics and Statistics 69, pp. 497-519.

Behrens, K., Mion, G., Murata, Y., Südekum, J., 2009. Trade, Wages and Productivity. Centre for Economic Policy Research Discussion Paper \#7369.

Bergin, P., Feenstra, R., 2000. Staggered Price Setting, Translog Preferences, and Endogenous Persistence. Journal of Monetary Economics 45, pp. 657-680.

Bergin, P., Feenstra, R., 2009. Pass-Through of Exchange Rates and Competition between Floaters and Fixers. Journal of Money, Credit and Banking 41S, pp. 35-70.

Bergstrand, J., 1985. The Gravity Equation in International Trade: Some Microeconomic Foundations and Empirical Evidence. Review of Economics and Statistics 67, pp. 474481.

Bergstrand, J., 1989. The Generalized Gravity Equation, Monopolistic Competition, and the Factor-Proportions Theory in International Trade. Review of Economics and Statistics 71, pp. 143-153.

Chaney, T., 2008. Distorted Gravity: The Intensive and Extensive Margins of International Trade. American Economic Review 98, pp. 1707-1721.

Chen, N., Imbs, J., Scott, A., 2009. The Dynamics of Trade and Competition. Journal of International Economics 77, pp. 50-62.

Christensen, L., Jorgenson, D., Lau, L., 1971. Conjugate Duality and the Transcendental Logarithmic Function. Econometrica 39, pp. 255-256.

Christensen, L., Jorgenson, D., Lau, L., 1975. Transcendental Logarithmic Utility Functions. American Economic Review 65, pp. 367-383.

Deardorff, A., 1998. Determinants of Bilateral Trade: Does Gravity Work in a Neoclassical World? In: Jeffrey A. Frankel (Ed.), The Regionalization of the World Economy. Chicago: University of Chicago Press.

Deaton, A., Muellbauer, J., 1980. An Almost Ideal Demand System. American Economic Review 70, pp. 312-326.

Diewert, W.E., 1976. Exact and Superlative Index Numbers. Journal of Econometrics 4, pp. 115145.

Disdier, A., Head, K., 2008. The Puzzling Persistence of the Distance Effect on Bilateral Trade. Review of Economics and Statistics 90, pp. 37-48.

Eaton, J., Kortum, S., 2002. Technology, Geography and Trade. Econometrica 70, pp. 17411779.

Evenett, S., Keller, W., 2002. On Theories Explaining the Success of the Gravity Equation. Journal of Political Economy 110, pp. 281-316.

Feenstra, R., 1994. New Product Varieties and the Measurement of International Prices. American Economic Review 84, pp. 157-177.

Feenstra, R., 2003. A Homothetic Utility Function for Monopolistic Competition Models, without Constant Price Elasticity. Economics Letters 78, pp. 79-86. 
Feenstra, R., Kee, H.L., 2008. Export Variety and Country Productivity: Estimating the Monopolistic Competition Model with Endogenous Productivity. Journal of International Economics 74, pp. 500-518.

Feenstra, R., Markusen, J., Rose, A., 2001. Using the Gravity Equation to Differentiate Among Alternative Theories of Trade. Canadian Journal of Economics 34, pp. 430-447.

Feenstra, R., Weinstein, D., 2010. Globalization, Markups, and the U.S. Price Level. National Bureau of Economic Research Working Paper \#15749.

Gohin, A., Féménia, F., 2009. Estimating Price Elasticities of Food Trade Functions. How Relevant is the CES-Based Gravity Approach? Journal of Agricultural Economics 60, pp. 253-272.

Helpman, E., Melitz, M., Rubinstein, Y., 2008. Estimating Trade Flows: Trading Partners and Trading Volumes. Quarterly Journal of Economics 123, pp. 441-487.

Hillberry, R., Hummels, D., 2008. Trade Responses to Geographic Frictions: A Decomposition Using Micro-Data. European Economic Review 52, pp. 527-550.

Hummels, D., Klenow, P., 2005. The Variety and Quality of a Nation's Exports. American Economic Review 95, pp. 704-723.

Kehoe, T., Ruhl, K., 2009. How Important is the New Goods Margin in International Trade? Federal Reserve Bank of Minneapolis Research Department, Staff Report 324.

Komorovska, J., Kuiper, M., van Tongeren, F., 2007. Sharing Gravity: Gravity Estimates of Trade Shares in Agri-Food. Working Paper, OECD.

Lo, L., 1990. A Translog Approach to Consumer Spatial Behavior. Journal of Regional Science 30, pp. 393-413.

Markusen, J., 1986. Explaining the Volume of Trade: An Eclectic Approach. American Economic Review 76, pp. 1002-1011.

Melitz, M., Ottaviano, G., 2008. Market Size, Trade, and Productivity. Review of Economic Studies 75, pp. 295-316.

Volpe Martincus, C., Estevadeordal, A., 2009. Trade Policy and Specialization in Developing Countries. Review of World Economics 145, pp. 251-275. 


\section{Technical Appendix}

This appendix outlines the derivation of the translog gravity equation (7). Substituting the expenditures shares implied by (4) into the market-clearing condition (6) yields

$$
y_{i}=\sum_{j=1}^{J} x_{i j}=\sum_{j=1}^{J} y_{j} \sum_{m=N_{i-1}+1}^{N_{i}} s_{m j}=\sum_{j=1}^{J} y_{j} \sum_{m=N_{i-1}+1}^{N_{i}}\left(\alpha_{m}+\sum_{k=1}^{N} \gamma_{k m} \ln \left(p_{k j}\right)\right) \text {. }
$$

Use $p_{k j}=t_{k j} p_{k}$ and define world income as $y^{W} \equiv \sum_{j=1}^{J} y_{j}$ to obtain

$$
y_{i}=\sum_{j=1}^{J} y_{j} \sum_{m=N_{i-1}+1}^{N_{i}}\left(\alpha_{m}+\sum_{k=1}^{N} \gamma_{k m} \ln \left(t_{k j}\right)\right)+y^{W} \sum_{m=N_{i-1}+1}^{N_{i}}\left(\sum_{k=1}^{N} \gamma_{k m} \ln \left(p_{k}\right)\right),
$$

which can be rearranged as

$$
\sum_{m=N_{i-1}+1}^{N_{i}}\left(\sum_{k=1}^{N} \gamma_{k m} \ln \left(p_{k}\right)\right)=\frac{y_{i}}{y^{W}}-\sum_{s=1}^{J} \frac{y_{s}}{y^{W}} \sum_{m=N_{i-1}+1}^{N_{i}}\left(\alpha_{m}+\sum_{k=1}^{N} \gamma_{k m} \ln \left(t_{k s}\right)\right),
$$

where the first summation index on the right-hand side is changed from $j$ to $s$.

Then substitute the last equation back into the import share (5):

$$
\begin{aligned}
\frac{x_{i j}}{y_{j}} & =\sum_{m=N_{i-1}+1}^{N_{i}}\left(\alpha_{m}+\sum_{k=1}^{N} \gamma_{k m} \ln \left(t_{k j}\right)\right)+\frac{y_{i}}{y^{W}}-\sum_{s=1}^{J} \frac{y_{s}}{y^{W}} \sum_{m=N_{i-1}+1}^{N_{i}}\left(\alpha_{m}+\sum_{k=1}^{N} \gamma_{k m} \ln \left(t_{k s}\right)\right) \\
& =\frac{y_{i}}{y^{W}}+\sum_{s=1}^{J} \frac{y_{s}}{y^{W}} \sum_{m=N_{i-1}+1}^{N_{i}}\left(\sum_{k=1}^{N} \gamma_{k m} \ln \left(t_{k j}\right)-\sum_{k=1}^{N} \gamma_{k m} \ln \left(t_{k s}\right)\right) \\
& =\frac{y_{i}}{y^{W}}+\sum_{s=1}^{J} \frac{y_{s}}{y^{W}} \sum_{m=N_{i-1}+1}^{N_{i}}\left(\sum_{k=1}^{N} \gamma_{k m} \ln \left(\frac{t_{k j}}{t_{k s}}\right)\right) .
\end{aligned}
$$

Use (3) to arrive at

$$
\begin{aligned}
\frac{x_{i j}}{y_{j}} & =\frac{y_{i}}{y^{W}}+\sum_{s=1}^{J} \frac{y_{s}}{y^{W}} \sum_{m=N_{i-1}+1}^{N_{i}}\left(\sum_{k=1, k \neq m}^{N} \frac{\gamma}{N} \ln \left(\frac{t_{k j}}{t_{k s}}\right)-\frac{\gamma}{N}(N-1) \ln \left(\frac{t_{m j}}{t_{m s}}\right)\right) \\
& =\frac{y_{i}}{y^{W}}+\sum_{s=1}^{J} \frac{y_{s}}{y^{W}} \sum_{m=N_{i-1}+1}^{N_{i}}\left(\sum_{k=1}^{N} \frac{\gamma}{N} \ln \left(\frac{t_{k j}}{t_{k s}}\right)-\gamma \ln \left(\frac{t_{m j}}{t_{m s}}\right)\right) .
\end{aligned}
$$

To ease notation define the geometric mean of trade costs in country $j$ as

$$
T_{j} \equiv\left(\prod_{k=1}^{N} t_{k j}\right)^{1 / N}
$$

so that

$$
\frac{x_{i j}}{y_{j}}=\frac{y_{i}}{y^{W}}+\sum_{s=1}^{J} \frac{y_{s}}{y^{W}} \sum_{m=N_{i-1}+1}^{N_{i}}\left(\gamma \ln \left(\frac{T_{j}}{T_{s}}\right)-\gamma \ln \left(\frac{t_{m j}}{t_{m s}}\right)\right) .
$$


Recall that $t_{m j}=t_{i j}$ if $m \in\left[N_{i-1}+1, N_{i}\right]$ so that the previous equation can be rewritten as

$$
\begin{aligned}
\frac{x_{i j}}{y_{j}} & =\frac{y_{i}}{y^{W}}+\sum_{s=1}^{J} \frac{y_{s}}{y^{W}} n_{i}\left(\gamma \ln \left(\frac{T_{j}}{T_{s}}\right)-\gamma \ln \left(\frac{t_{i j}}{t_{i s}}\right)\right) \\
& =\frac{y_{i}}{y^{W}}-\gamma n_{i} \ln \left(t_{i j}\right)+\gamma n_{i} \ln \left(T_{j}\right)+\gamma n_{i} \sum_{s=1}^{J} \frac{y_{s}}{y^{W}} \ln \left(\frac{t_{i s}}{T_{s}}\right),
\end{aligned}
$$

where $n_{i} \equiv N_{i}-N_{i-1}$ denotes the number of goods of country $i$. Note that $\ln \left(T_{j}\right)$ can be rewritten as a weighted average of trade costs over the trading partners of country $j$ :

$$
\ln \left(T_{j}\right)=\frac{1}{N} \sum_{k=1}^{N} \ln \left(t_{k j}\right)=\sum_{s=1}^{J} \frac{n_{s}}{N} \ln \left(t_{s j}\right) .
$$




\section{Table 1: Translog gravity}

\begin{tabular}{|c|c|c|c|c|c|c|}
\hline \multirow[b]{2}{*}{ Dependent variable } & \multicolumn{4}{|c|}{ Multiple goods per country } & \multicolumn{2}{|c|}{ One good per country $\left(n_{i}=1\right)$} \\
\hline & $\begin{array}{c}x_{i j} / y_{j} \\
(1)\end{array}$ & $\begin{array}{c}x_{i j} / y_{j} \\
(2) \\
\end{array}$ & $\begin{array}{c}\left(x_{i j} / y_{j}\right) / n_{i} \\
(3)\end{array}$ & $\begin{array}{c}\left(x_{i j} / y_{j}\right) / n_{i} \\
(4)\end{array}$ & $\begin{array}{c}x_{i j} / y_{j} \\
(5) \\
\end{array}$ & $\begin{array}{c}x_{i j} / y_{j} \\
(6)\end{array}$ \\
\hline $\mathrm{n}_{\mathrm{i}} \ln \left(\right.$ dist $\left._{\mathrm{ij}}\right)$ & $\begin{array}{c}-0.0296^{* * *} \\
(0.0041)\end{array}$ & $\begin{array}{c}-0.0190 * * * \\
(0.0029)\end{array}$ & & & & \\
\hline $\mathrm{n}_{\mathrm{i}} \ln \left(\mathrm{T}_{\mathrm{j}}^{\text {dist }}\right)$ & $\begin{array}{c}0.0207^{* * *} \\
(0.0049)\end{array}$ & $\begin{array}{c}0.0105^{* * *} \\
(0.0034)\end{array}$ & & & & \\
\hline $\mathrm{n}_{\mathrm{i}} \operatorname{adj}_{\mathrm{ij}}$ & & $\begin{array}{c}0.0510 * * * \\
(0.0117)\end{array}$ & & & & \\
\hline $\mathrm{n}_{\mathrm{i}} \mathrm{T}_{\mathrm{j}}^{\mathrm{adj}}$ & & $\begin{array}{c}-0.0471^{* *} \\
(0.0192)\end{array}$ & & & & \\
\hline $\ln \left(\right.$ dist $\left._{\mathrm{ij}}\right)$ & & & $\begin{array}{c}-0.0250 * * * \\
(0.0033)\end{array}$ & $\begin{array}{c}-0.0159 * * * \\
(0.0021)\end{array}$ & $\begin{array}{c}-0.0149 * * * \\
(0.0022)\end{array}$ & $\begin{array}{c}-0.0094 * * * \\
(0.0016)\end{array}$ \\
\hline $\operatorname{adj}_{\mathrm{ij}}$ & & & & $\begin{array}{c}0.0450 * * * \\
(0.0090)\end{array}$ & & $\begin{array}{c}0.0273 * * * \\
(0.0053)\end{array}$ \\
\hline R-squared & 0.52 & 0.59 & 0.50 & 0.57 & 0.50 & 0.56 \\
\hline Observations & 749 & 749 & 749 & 749 & 749 & 749 \\
\hline
\end{tabular}

Notes: Data for the year 2000. Robust standard errors clustered around country pairs (378 clusters) reported in parentheses, OLS estimation. Columns 1 and 2: exporter fixed effects not reported. Columns 3-6: exporter and importer fixed effects not reported. ${ }^{* *}$ significant at $5 \%$ level. ${ }^{* * *}$ significant at $1 \%$ level. 
Table 2: Constant elasticity gravity

\begin{tabular}{lcc|cc} 
Dependent variable & $\begin{array}{c}\ln \left(\mathrm{x}_{\mathrm{ij}} / \mathrm{y}_{\mathrm{j}}\right) \\
(1)\end{array}$ & $\begin{array}{c}\ln \left(\mathrm{x}_{\mathrm{ij}} / \mathrm{y}_{\mathrm{j}}\right) \\
(2)\end{array}$ & $\begin{array}{c}\ln \left(\left(\mathrm{x}_{\mathrm{ij}} / \mathrm{y}_{\mathrm{j}}\right) / \mathrm{n}_{\mathrm{i}}\right) \\
(3)\end{array}$ & $\begin{array}{c}\ln \left(\left(\mathrm{x}_{\mathrm{ij}} / \mathrm{y}_{\mathrm{j}}\right) / \mathrm{n}_{\mathrm{i}}\right) \\
(4)\end{array}$ \\
\hline $\ln \left(\right.$ dist $\left._{\mathrm{ij}}\right)$ & $-1.2390^{* * *}$ & $-1.1697^{* * *}$ & $-1.2390^{* * *}$ & $-1.1697^{* * *}$ \\
& $(0.0625)$ & $(0.0713)$ & $(0.0625)$ & $(0.0713)$ \\
$\operatorname{adj}_{\mathrm{ij}}$ & & $0.3440^{* *}$ & & $0.3440^{* *}$ \\
& & $(0.1720)$ & & $(0.1720)$ \\
& & & & \\
R-squared & 0.89 & 0.89 & 0.85 & 0.85 \\
Observations & 749 & 749 & 749 & 749 \\
\hline
\end{tabular}

Notes: Data for the year 2000. Robust standard errors clustered around country pairs (378 clusters) reported in parentheses, OLS estimation. The coefficients in columns 1 and 2 are the same as in columns 3 and 4 . Exporter and importer fixed effects not reported. ${ }^{* *}$ significant at $5 \%$ level. ${ }^{* * *}$ significant at $1 \%$ level. 
Table 3: Testing constant elasticity gravity against translog gravity (Hypothesis A)

\begin{tabular}{|c|c|c|c|c|c|c|}
\hline \multirow[b]{2}{*}{ Dependent variable } & \multicolumn{4}{|c|}{ Intervals based on $\left(x_{i j} / y_{j}\right) / n_{i}$} & \multicolumn{2}{|c|}{ Intervals based on $\left(x_{i j} / y_{j}\right)$} \\
\hline & $\begin{array}{c}\ln \left(x_{i j} / y_{j}\right) \\
(1) \\
\end{array}$ & $\begin{array}{c}\ln \left(x_{i j} / y_{j}\right) \\
(2) \\
\end{array}$ & $\begin{array}{c}\ln \left(\left(x_{i j} / y_{j}\right) / n_{i}\right) \\
(3)\end{array}$ & $\begin{array}{c}\ln \left(\left(x_{\mathrm{ij}} / \mathrm{y}_{\mathrm{j}}\right) / \mathrm{n}_{\mathrm{i}}\right) \\
(4)\end{array}$ & $\begin{array}{c}\ln \left(x_{i j} / y_{j}\right) \\
(5) \\
\end{array}$ & $\begin{array}{c}\ln \left(x_{i j} / y_{j}\right) \\
(6) \\
\end{array}$ \\
\hline $\ln \left(\right.$ dist $\left._{i j}\right), h=1$ & $\begin{array}{c}-1.4960 * * * \\
(0.1377)\end{array}$ & $\begin{array}{c}-1.4490 * * * \\
(0.1313)\end{array}$ & $\begin{array}{c}-1.4960 * * * \\
(0.1377)\end{array}$ & $\begin{array}{c}-1.4490 * * * \\
(0.1313)\end{array}$ & $\begin{array}{c}-1.6523 * * * \\
(0.1080)\end{array}$ & $\begin{array}{c}-1.5970 * * * \\
(0.1044)\end{array}$ \\
\hline $\ln \left(\right.$ dist $\left._{\mathrm{ij}}\right), \mathrm{h}=2$ & $\begin{array}{c}-1.4636^{* * *} \\
(0.1223)\end{array}$ & $\begin{array}{c}-1.3405^{* * *} \\
(0.1117)\end{array}$ & $\begin{array}{c}-1.4636 * * * \\
(0.1223)\end{array}$ & $\begin{array}{c}-1.3405^{* * *} \\
(0.1117)\end{array}$ & $\begin{array}{c}-1.3936 * * * \\
(0.1180)\end{array}$ & $\begin{array}{c}-1.3190 * * * \\
(0.1140)\end{array}$ \\
\hline $\ln \left(\right.$ dist $\left._{i j}\right), h=3$ & $\begin{array}{c}-1.3668 * * * \\
(0.1092)\end{array}$ & $\begin{array}{c}-1.2502^{* * *} \\
(0.1043)\end{array}$ & $\begin{array}{c}-1.3668 * * * \\
(0.1092)\end{array}$ & $\begin{array}{c}-1.2502 * * * \\
(0.1043)\end{array}$ & $\begin{array}{c}-1.3369 * * * \\
(0.1123)\end{array}$ & $\begin{array}{c}-1.2131^{* * *} \\
(0.1017)\end{array}$ \\
\hline $\ln \left(\right.$ dist $\left._{i j}\right), h=4$ & $\begin{array}{c}-1.2235^{* * *} \\
(0.1024)\end{array}$ & $\begin{array}{c}-1.0662 * * * \\
(0.0968)\end{array}$ & $\begin{array}{c}-1.2235 * * * \\
(0.1024)\end{array}$ & $\begin{array}{c}-1.0662 * * * \\
(0.0968)\end{array}$ & $\begin{array}{c}-1.3311^{* * *} \\
(0.0947)\end{array}$ & $\begin{array}{c}-1.1551 * * * \\
(0.0946)\end{array}$ \\
\hline $\ln \left(\right.$ dist $\left._{i j}\right), h=5$ & $\begin{array}{c}-1.0790 * * * \\
(0.1000)\end{array}$ & $\begin{array}{c}-0.8297 * * * \\
(0.1045)\end{array}$ & $\begin{array}{c}-1.0790 * * * \\
(0.1000)\end{array}$ & $\begin{array}{c}-0.8297 * * * \\
(0.1045)\end{array}$ & $\begin{array}{c}-1.0662 * * * \\
(0.0910)\end{array}$ & $\begin{array}{c}-0.8251 * * * \\
(0.0972)\end{array}$ \\
\hline $\operatorname{adj}_{\mathrm{ij}}, \mathrm{h}=2$ & & $\begin{array}{c}1.9499 * * * \\
(0.2279)\end{array}$ & & $\begin{array}{c}1.9499 * * * \\
(0.2279)\end{array}$ & & $\begin{array}{l}1.1283^{*} \\
(0.6657)\end{array}$ \\
\hline $\operatorname{adj}_{\mathrm{ij}}, \mathrm{h}=3$ & & $\begin{array}{c}2.3218^{* * *} \\
(0.2150)\end{array}$ & & $\begin{array}{c}2.3218^{* * *} \\
(0.2150)\end{array}$ & & $\begin{array}{c}1.6318^{* * *} \\
(0.5925)\end{array}$ \\
\hline $\operatorname{adj}_{\mathrm{ij}}, \mathrm{h}=4$ & & $\begin{array}{c}0.7333^{* * *} \\
(0.2345)\end{array}$ & & $\begin{array}{c}0.7333 * * * \\
(0.2345)\end{array}$ & & $\begin{array}{c}0.5197 * * * \\
(0.1910)\end{array}$ \\
\hline $\operatorname{adj}_{\mathrm{ij}}, \mathrm{h}=5$ & & $\begin{array}{c}0.6221^{* * *} \\
(0.1500)\end{array}$ & & $\begin{array}{c}0.6221 * * * \\
(0.1500)\end{array}$ & & $\begin{array}{c}0.6359 * * * \\
(0.1556)\end{array}$ \\
\hline R-squared & 0.90 & 0.90 & 0.86 & 0.87 & 0.89 & 0.90 \\
\hline Observations & 749 & 749 & 749 & 749 & 749 & 749 \\
\hline
\end{tabular}

Notes: Data for the year 2000. The index $\mathrm{h}$ denotes intervals in order of ascending predicted import shares. The intervals in columns 1-4 are based on predicted import shares divided by $n_{i}$. The intervals in columns 5 and 6 are based on predicted import shares only. The $\operatorname{adj}_{\mathrm{ij}}$ regressor for interval $\mathrm{h}=1$ drops out since no adjacent country pair falls into this interval. Robust standard errors clustered around country pairs (378 clusters) reported in parentheses, OLS estimation. Exporter and importer fixed effects and interval fixed effects not reported. The coefficients in columns 1 and 2 are the same as in columns 3 and $4 .{ }^{*}$ significant at $10 \%$ level. ${ }^{* *}$ significant at $5 \%$ level. ${ }^{* * *}$ significant at $1 \%$ level. 
Table 4a: Testing translog gravity against constant elasticity gravity (Hypothesis B)

\begin{tabular}{|c|c|c|}
\hline \multirow[b]{2}{*}{ Dependent variable } & \multicolumn{2}{|c|}{ Intervals based on $\left(x_{i j} / y_{j}\right) / n_{i}$} \\
\hline & $\begin{array}{c}\left(x_{i j} / y_{j}\right) / n_{i} \\
(1)\end{array}$ & $\begin{array}{c}\left(x_{i j} / y_{j}\right) / n_{i} \\
(2)\end{array}$ \\
\hline $\ln \left(\right.$ dist $\left._{\mathrm{ij}}\right), \mathrm{h}=1$ & $\begin{array}{c}-0.0449 * * * \\
(0.0068)\end{array}$ & $\begin{array}{c}-0.0347^{* * *} \\
(0.0039)\end{array}$ \\
\hline $\ln \left(\right.$ dist $\left._{i j}\right), h=2$ & $\begin{array}{c}-0.0518 * * * \\
(0.0077)\end{array}$ & $\begin{array}{c}-0.0383 * * * \\
(0.0042)\end{array}$ \\
\hline $\ln \left(\right.$ dist $\left._{\mathrm{ij}}\right), \mathrm{h}=3$ & $\begin{array}{c}-0.0516 * * * \\
(0.0078)\end{array}$ & $\begin{array}{c}-0.0412 * * * \\
(0.0046)\end{array}$ \\
\hline $\ln \left(\right.$ dist $\left._{\mathrm{ij}}\right), \mathrm{h}=4$ & $\begin{array}{c}-0.0543 * * * \\
(0.0079)\end{array}$ & $\begin{array}{c}-0.0411^{* * *} \\
(0.0045)\end{array}$ \\
\hline $\ln \left(\right.$ dist $\left._{\mathrm{ij}}\right), \mathrm{h}=5$ & $\begin{array}{c}-0.0567^{* * *} \\
(0.0084)\end{array}$ & $\begin{array}{c}-0.0380 * * * \\
(0.0057)\end{array}$ \\
\hline $\operatorname{adj}_{\mathrm{ij}}, \mathrm{h}=5$ & & $\begin{array}{c}0.0608 * * * \\
(0.0103)\end{array}$ \\
\hline R-squared & 0.64 & 0.71 \\
\hline Observations & 749 & 749 \\
\hline $\begin{array}{l}\text { Notes: Data for the yea } \\
\text { order of ascending prec } \\
\text { based on predicted imp } \\
\text { regressors for intervals } \\
\text { adjacent country pair } \\
\text { standard errors cluster } \\
\text { reported in parenthese } \\
\text { importer fixed effects a } \\
*_{* *} \text { significant at } 1 \% \text { le }\end{array}$ & $\begin{array}{l}\text { The index } \mathrm{h} \text { de } \\
\text { mport shares. T } \\
\text { res divided by } \\
\text { drop out in colu } \\
\text { these intervals } \\
\text { nd country pai } \\
\text { estimation. Exp } \\
\text { rval fixed effec }\end{array}$ & $\begin{array}{l}\text { tes intervals in } \\
\text { intervals are } \\
\text { The adj } \mathrm{j}_{\mathrm{ij}} \\
2 \text { since no } \\
\text { obust } \\
378 \text { clusters) } \\
\text { er and } \\
\text { ot reported. }\end{array}$ \\
\hline
\end{tabular}


Table 4b: Testing translog gravity against constant elasticity gravity (Hypothesis B)

\begin{tabular}{|c|c|c|c|c|}
\hline \multirow[b]{2}{*}{ Dependent variable } & \multicolumn{2}{|c|}{ Intervals based on $\left(x_{i j} / y_{j}\right) / n_{i}$} & \multicolumn{2}{|c|}{ Intervals based on $\left(x_{i j} / y_{j}\right)$} \\
\hline & $\begin{array}{c}\mathrm{x}_{\mathrm{ij}} / \mathrm{y}_{\mathrm{j}} \\
(1)\end{array}$ & $\begin{array}{c}x_{i j} / y_{j} \\
(2)\end{array}$ & $\begin{array}{c}\mathrm{x}_{\mathrm{ij}} / \mathrm{y}_{\mathrm{j}} \\
(3) \\
\end{array}$ & $\begin{array}{c}x_{i j} / y_{j} \\
(4)\end{array}$ \\
\hline$n_{i} \ln \left(\right.$ dist $\left._{i j}\right), h=1$ & $\begin{array}{c}-0.0535^{* * *} \\
(0.0090)\end{array}$ & $\begin{array}{c}-0.0406^{* * *} \\
(0.0064)\end{array}$ & $\begin{array}{c}-0.0403^{* * *} \\
(0.0085)\end{array}$ & $\begin{array}{c}-0.0369 * * * \\
(0.0061)\end{array}$ \\
\hline $\mathrm{n}_{\mathrm{i}} \ln \left(\right.$ dist $\left._{\mathrm{ij}}\right), \mathrm{h}=2$ & $\begin{array}{c}-0.0446 * * * \\
(0.0081)\end{array}$ & $\begin{array}{c}-0.0351^{* * *} \\
(0.0052)\end{array}$ & $\begin{array}{c}-0.0338 * * * \\
(0.0075)\end{array}$ & $\begin{array}{c}-0.0327^{* * *} \\
(0.0054)\end{array}$ \\
\hline$n_{i} \ln \left(\right.$ dist $\left._{i j}\right), h=3$ & $\begin{array}{c}-0.0507^{* * *} \\
(0.0085)\end{array}$ & $\begin{array}{c}-0.0376^{* * *} \\
(0.0054)\end{array}$ & $\begin{array}{c}-0.0334 * * * \\
(0.0069)\end{array}$ & $\begin{array}{c}-0.0337^{* * *} \\
(0.0053)\end{array}$ \\
\hline $\mathrm{n}_{\mathrm{i}} \ln \left(\right.$ dist $\left._{\mathrm{ij}}\right), \mathrm{h}=4$ & $\begin{array}{c}-0.0585^{* * *} \\
(0.0095)\end{array}$ & $\begin{array}{c}-0.0406 * * * \\
(0.0062)\end{array}$ & $\begin{array}{c}-0.0332 * * * \\
(0.0061)\end{array}$ & $\begin{array}{c}-0.0343^{* * *} \\
(0.0055)\end{array}$ \\
\hline$n_{i} \ln \left(\right.$ dist $\left._{i j}\right), h=5$ & $\begin{array}{c}-0.0627^{* * *} \\
(0.0087)\end{array}$ & $\begin{array}{c}-0.0476^{* * *} \\
(0.0077)\end{array}$ & $\begin{array}{c}-0.0601 * * * \\
(0.0079)\end{array}$ & $\begin{array}{c}-0.0439 * * * \\
(0.0084)\end{array}$ \\
\hline $\mathrm{n}_{\mathrm{i}} \ln \left(\mathrm{T}_{\mathrm{j}}^{\text {dist }}\right), \mathrm{h}=1$ & $\begin{array}{c}0.0430 * * * \\
(0.0076)\end{array}$ & $\begin{array}{c}0.0286^{* * *} \\
(0.0049)\end{array}$ & $\begin{array}{c}0.0291 * * * \\
(0.0065)\end{array}$ & $\begin{array}{c}0.0258 * * * \\
(0.0047)\end{array}$ \\
\hline $\mathrm{n}_{\mathrm{i}} \ln \left(\mathrm{T}_{\mathrm{j}}^{\text {dist }}\right), \mathrm{h}=2$ & $\begin{array}{c}0.0300 * * * \\
(0.0067)\end{array}$ & $\begin{array}{c}0.0189 * * * \\
(0.0037)\end{array}$ & $\begin{array}{c}0.0201 * * * \\
(0.0057)\end{array}$ & $\begin{array}{c}0.0183 * * * \\
(0.0039)\end{array}$ \\
\hline $\mathrm{n}_{\mathrm{i}} \ln \left(\mathrm{T}_{\mathrm{j}}^{\text {dist }}\right), \mathrm{h}=3$ & $\begin{array}{c}0.0343 * * * \\
(0.0072)\end{array}$ & $\begin{array}{c}0.0199 * * * \\
(0.0043)\end{array}$ & $\begin{array}{c}0.0195^{* * *} \\
(0.0058)\end{array}$ & $\begin{array}{c}0.0189 * * * \\
(0.0040)\end{array}$ \\
\hline $\mathrm{n}_{\mathrm{i}} \ln \left(\mathrm{T}_{\mathrm{j}}^{\text {dist }}\right), \mathrm{h}=4$ & $\begin{array}{c}0.0391^{* * *} \\
(0.0085)\end{array}$ & $\begin{array}{c}0.0207^{* * *} \\
(0.0055)\end{array}$ & $\begin{array}{c}0.0184 * * * \\
(0.0055)\end{array}$ & $\begin{array}{c}0.0163 * * * \\
(0.0044)\end{array}$ \\
\hline $\mathrm{n}_{\mathrm{i}} \ln \left(\mathrm{T}_{\mathrm{j}}^{\text {dist }}\right), \mathrm{h}=5$ & $\begin{array}{c}0.0417^{* * *} \\
(0.0084)\end{array}$ & $\begin{array}{c}0.0256^{* * *} \\
(0.0067)\end{array}$ & $\begin{array}{c}0.0413^{* * *} \\
(0.0083)\end{array}$ & $\begin{array}{c}0.0242 * * * \\
(0.0079)\end{array}$ \\
\hline$n_{i} \operatorname{adj}_{i j}, h=5$ & & $\begin{array}{c}0.0536 * * * \\
(0.0161)\end{array}$ & & $\begin{array}{c}0.0529 * * * \\
(0.0161)\end{array}$ \\
\hline $\mathrm{n}_{\mathrm{i}} \mathrm{T}_{\mathrm{j}}^{\mathrm{adj}}, \mathrm{h}=5$ & & $\begin{array}{c}-0.1309 * * \\
(0.0647)\end{array}$ & & $\begin{array}{c}-0.0933^{*} \\
(0.0501)\end{array}$ \\
\hline R-squared & 0.64 & 0.69 & 0.64 & 0.68 \\
\hline Observations & 749 & 749 & 749 & 749 \\
\hline
\end{tabular}

Notes: Data for the year 2000. The index $h$ denotes intervals in order of ascending predicted import shares. The intervals in columns 1 and 2 are based on predicted import shares divided by $n_{i}$. The intervals in columns 3 and 4 are based on predicted import shares only. The $n_{i}$ adj $j_{i j}$ regressors for intervals $h=1-4$ drop out in column 2 since no adjacent country pairs fall into these intervals (intervals $h=1,2$ and 4 in column 4). The $n_{i} T_{j}^{\text {adj }}$ regressors for intervals $h=1-4$ in columns 2 and 4 are included but not reported here. Robust standard errors clustered around country pairs (378 clusters) reported in parentheses, OLS estimation. Exporter fixed effects and interval fixed effects not reported. * significant at $10 \%$ level. ${ }^{* *}$ significant at $5 \%$ level. ${ }^{* * *}$ significant at $1 \%$ level. 
Table 5: General equilibrium effects in response to a counterfactual decline in trade costs

\begin{tabular}{|c|c|c|c|c|c|c|c|c|c|c|c|}
\hline \multirow[b]{2}{*}{ Import share interval } & \multirow{2}{*}{$\begin{array}{c}\text { Total effect } \\
\Delta \ln \left(\mathrm{x}_{\mathrm{ij}} / \mathrm{y}_{\mathrm{j}}\right) \\
(1)\end{array}$} & \multirow[b]{2}{*}{$=$} & \multirow{2}{*}{$\begin{array}{c}\text { Direct effect } \\
(1-\sigma) \Delta \ln \left(t_{\mathrm{ij}}\right) \\
(2)\end{array}$} & \multicolumn{4}{|c|}{ Indirect GE effect } & \multicolumn{2}{|c|}{ Trade cost elasticity } & \multicolumn{2}{|c|}{ Distance elasticity } \\
\hline & & & & + & $\begin{array}{c}\Delta \ln \left(y_{i} / y^{w}\right) \\
(3)\end{array}$ & + & $\begin{array}{c}(\sigma-1) \Delta \ln \left(P_{i} P_{j}\right) \\
(4)\end{array}$ & $\begin{array}{l}\text { Total } \\
\text { (5a) }\end{array}$ & $\begin{array}{l}\text { Direct } \\
(5 b)\end{array}$ & $\begin{array}{l}\text { Total } \\
\text { (6a) }\end{array}$ & $\begin{array}{l}\text { Direct } \\
(6 b)\end{array}$ \\
\hline$h=1$ & 0.0702 & $=$ & 0.07 & + & -0.0007 & + & 0.0009 & -7.02 & -7 & -1.00 & -1 \\
\hline$h=2$ & 0.0699 & $=$ & 0.07 & + & -0.0007 & + & 0.0007 & -6.99 & -7 & -1.00 & -1 \\
\hline$h=3$ & 0.0696 & $=$ & 0.07 & + & -0.0008 & + & 0.0003 & -6.96 & -7 & -0.99 & -1 \\
\hline$h=4$ & 0.0690 & $=$ & 0.07 & + & -0.0006 & + & -0.0003 & -6.90 & -7 & -0.99 & -1 \\
\hline$h=5$ & 0.0637 & $=$ & 0.07 & + & -0.0007 & + & -0.0056 & -6.37 & -7 & -0.91 & -1 \\
\hline \multicolumn{12}{|c|}{$\begin{array}{l}\text { Notes: This table reports logarithmic differences of variables between the initial equilibrium and the counterfactual equilibrium. The initial equilibrium is based } \\
\text { on country income shares } \mathrm{y}_{\mathrm{i}} / \mathrm{y}^{\mathrm{w}} \text { for the year } 2000 \text { and bilateral distance data for the } 28 \text { countries in the sample }(28 * 27=756 \text { bilateral observations). For each } \\
\text { bilateral observation a counterfactual equilibrium is computed under the assumption that bilateral trade costs } t_{i j} \text { for this observation have decreased by one } \\
\text { percent all else being equal, yielding } 756 \text { counterfactual scenarios. The table reports the logarithmic differences between the initial and the counterfactual } \\
\text { equilibria averaged across five import share intervals denoted by h. Import share intervals are in ascending order and based on the initial equilibrium. Assumed } \\
\text { parameter values: } \sigma=8 \text { and } \rho=1 / 7 \text {. Column } 1 \text { : change in the import share; column } 2: \text { change in bilateral trade costs scaled by the substitution elasticity; column } \\
\text { 3: change in the exporting country's income share; column } 4: \text { change in multilateral resistance scaled by the substitution elasticity; columns } 5 \text { a and } 5 \text { b: implied } \\
\text { trade cost elasticities based on total effect and direct effect }(=1-\sigma) \text {; columns } 6 \text { a and } 6 \mathrm{~b} \text { : implied distance elasticities based on total effect and direct effect }(=(1- \\
\left.\sigma)^{*} \rho\right) \text {. }\end{array}$} \\
\hline
\end{tabular}




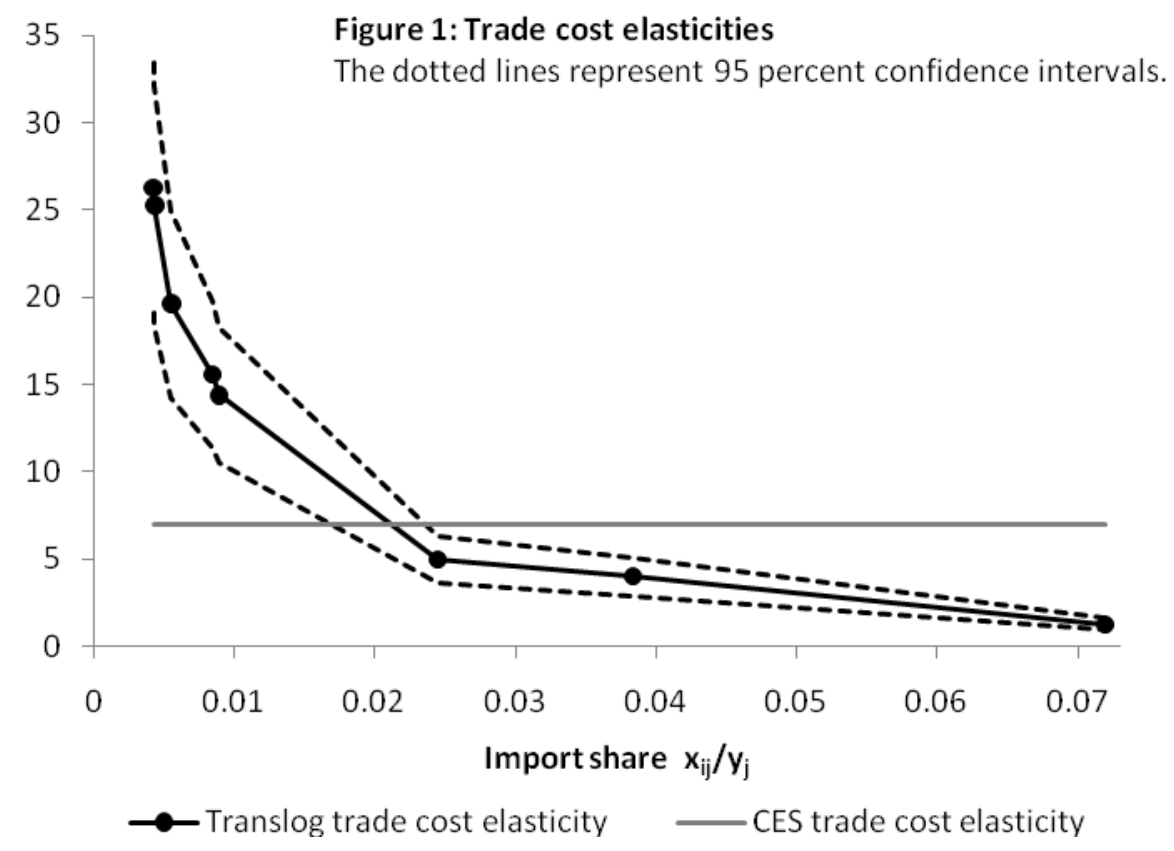




\section{CENTRE FOR ECONOMIC PERFORMANCE \\ Recent Discussion Papers}

1030 Alex Bryson

John Forth

1029 Fabrice Defever

1028 Elhanan Helpman

Oleg Itskhoki

Stephen Redding

1027 Nicholas Oulton

1026 Maarten Goos

Alan Manning

Anna Salomons

1025 David H. Autor

Alan Manning

Christopher L. Smith

1024 Pascal Michaillat

1023 Friederike Niepmann

Tim Schmidt-Eisenlohr

1022 Bianca De Paoli

Hande Küçük-Tuger

Jens Søndergaard

1021 Monika Mrázová

David Vines

Ben Zissimos

1020 Gianluca Benigno

Huigang Chen

Chris Otrok

Alessandro Rebucci

Eric Young

1019 Alex Bryson

Babatunde Buraimo

Rob Simmons

1018 Radha Iyengar
The Evolution of the Modern Worker:

Attitudes to Work

The Spatial Organization of Multinational

Firms

Trade and Labor Market Outcomes

Long Term Implications of the ICT

Revolution: Applying the Lessons of Growth

Theory and Growth Accounting

Explaining Job Polarization in Europe: the

Roles of Technology, Globalization and

Institutions

The Contribution of the Minimum Wage to

U.S. Wage Inequality over Three Decades: A

Reassessment

Do Matching Frictions Explain

Unemployment? Not in Bad Times

Bank Bailouts, International Linkages and

Cooperation

Monetary Policy Rules and Foreign Currency

Positions

Is the WTO Article XXIV Bad?

Revisiting Overborrowing and its Policy Implications

Do Salaries Improve Worker Performance?

The Impact of Asymmetric Information Among Competing Insurgent Groups:

Estimating an 'Emboldenment' Effect 
1017 Radha Iyengar

1016 Ethan Ilzetzki

Enrique G. Mendoza

Carlos A. Végh

1015 Kerry L. Papps

Alex Bryson

Rafael Gomez

1014 Kosuke Aoki

Gianluca Benigno

Nobuhiro Kiyotaki

1013 Luis Garicano

Yanhui Wu

1012 Olivier Marie

1011 Erling Barth

Alex Bryson

Harald Dale-Olsen

1010 Radha Iyengar

Giulia Ferrari

1009 Timothy Besley

Torsten Persson

Daniel M. Sturm

1008 Marco Manacorda

Furio Camillo Rosati

1007 Peter Dolton

Chiara Rosazza-Bondibene Jonathan Wadsworth

1006 David Marsden

1005 Sharon Belenzon

Mark Schankerman
I'd Rather be Hanged for a Sheep than a

Lamb

The Unintended Consequences of 'Three-

Strikes' Laws

How Big (Small?) are Fiscal Multipliers?

Heterogeneous Worker Ability and Team-

Based Production: Evidence from Major

League Baseball, 1920-2009

Adjusting to Capital Account Liberalization

A Task-Based Approach to Organization:

Knowledge, Communication and Structure

Police and Thieves in the Stadium: Measuring the (Multiple) Effects of Football Matches on

Crime

Do Higher Wages Come at a Price?

Discussion Sessions Coupled with

Microfinancing May Enhance the Roles of Women in Household Decision-Making in Burundi

Political Competition, Policy and Growth: Theory and Evidence from the United States

Industrial Structure and Child Labor:

Evidence from the Brazilian Population

Census

Employment, Inequality and the UK Naitonal

Minimum Wage over the Medium-Term

Individual Voice in Employment

Relationships: A Comparison Under Different

Collective Voice Regimes

Spreading the Word: Geography, Policy and

University Knowledge Diffusion

The Centre for Economic Performance Publications Unit

Tel 02079557284 Fax 02079557595

Email info@cep.lse.ac.uk Web site http://cep.lse.ac.uk 